\title{
Recent advances on oxadiazole motifs: Synthesis, reactions and biological activities
}

\author{
Olayinka O. Ajani * and King T. Iyaye \\ Department of Chemistry, CST, Covenant University. Km 10, Idiroko Road, PMB 1023, Ota, Nigeria
}

\begin{abstract}
: 1,3,4-oxadiazole derivatives have shown to have diverse and vast applications, from medicinal chemistry for the treatment and possible treatment of various ailments to its application in the industrial development when used as corrosion inhibitors and light-emitting diodes. These diverse life-changing applications can be as a result of the numerous viable synthetic pathways which afforded 1,3,4-oxadiazoles in very high yields, using green approaches. This review explores the various recent synthetic routes available for the development of 1,3,4-oxadiazoles and their biological activities.
\end{abstract}

Keywords: 1,3,4-oxadiazoles; reactions; synthesis; biological activities.

\section{Introduction}

Heterocyclic compounds have been subjected to intense research over the years, and they continue to attract multiple attention due to their immense contributions in the advancement of medicinal chemistry and industrial development ${ }^{1,2}$. They are utilized in medicinal chemistry as they are usually found in large amounts in biomolecules such as vitamins, enzymes, natural products and biological active compounds used in the treatment of various ailments such as malaria, convulsion, inflammations, HIV and even in the control of food destroying pest and insects ${ }^{3-7}$. Those containing nitrogen have been very eminent, even during the genesis of synthetic chemistry and in synthetic drug design. Oxadiazole is a heterocyclic scaffold which has attracted many interests due to the application of its derivatives in drug-related synthesis and other nonmedicinal applications. Oxadiazoles contain two nitrogen and one oxygen atoms in a five-membered ring and have four different isomeric forms ${ }^{8}$. Previously oxadiazoles have not been reported to occur in nature, however, in 2011, Carbone and co-workers isolated 1,2,4-oxadiazole derivatives from Phidiana militaris and the two isolated phidianidines A and B (1a \& b) showed very potent activity against tumor cell lines (C6, HeLa and CaCo-2) and 3T3-L1 tumor-free cell lines ${ }^{9}$. Furthermore, Brogan and co-workers were able to synthesize the phidianidines A and B $(\mathbf{1 a} \& \mathbf{b})$ in yields of $39.9 \%$ and $21 \%$ respectively and the oxadiazoles showed no toxicity at all and binding

Corresponding author: Olayinka O. Ajani

Email address: ola.ajani@covenantuniversity.edu.ng DOI: http://dx.doi.org/10.13171/mjc10502005121200ooa selectively to various CNS sites such as the $\mu$ opioid receptor which could enhance the potential of oxadiazole in pain treatment and other CNS related diseases ${ }^{10}$. The structural complexity and diverse biological use of functionalized oxadiazoles and their derivatives made them outstanding targets over the years. Oxadiazoles have shown potency as useful therapeutic medicine, possessing numerous biological and pharmacological activities which include antibacterial, antiviral, anti-inflammatory, antioxidant, antitumor, antiparasitic, antitubercular, antidepressant and many others ${ }^{11-15}$.

For instance, commercially available drugs containing oxadiazole includes Butalamine (a vasodilator), Oxalamine (a cough suppressant), Pleconaril (suppresses asthmatic symptoms), Fasiplon (an anxiolytic drug), Raltegravir (an antiretroviral drug), furamizole (an antibiotic) butyl PBD (a liquid scintillator neutrino, Zibotentan (anticancer) and Nesapidil (anti-hypertensive).

Asides medicinal purposes, oxadiazoles also found application in various agricultural and industrial sections. Polymers containing oxadiazole linkages have been reported as potent ambipolar hosts for phosphorescent light-emitting diodes ${ }^{16}$. Similarly, POC polymer containing oxadiazole-carbazole as monomers were mixed with $\operatorname{Ir}(\mathrm{ppy})$ and the resulting composite showed enhanced light-emitting properties. The properties could be utilized in the production of organic light-emitting diode (OLED) ${ }^{17}$.

Received August 22, 2019

Accepted October 2, 2019

Published May 12, 2020 
World population is ever-increasing, optimization of agricultural practices leading to higher demand of food production is essential. Oxadiazole derivatives are playing their part in increasing food production as they have also been reported to show herbicidal properties against Brassica campestris and Amaranthus retroflexus with compound (2) having the highest activity of $98 \%{ }^{18}$.<smiles>[R]c1ccc2c(Cc3nc(NCCCCCNC(=N)N)no3)c[nH]c2c1</smiles>

a: $\mathrm{R}=\mathrm{Br}$ (phidianidine $\mathrm{A}$ ) b: $\mathbf{R}=\mathbf{H}$ (Phidianidine B)

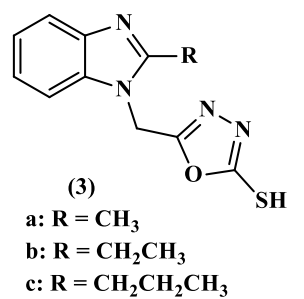

Corrosion is a momentous challenge plaguing industrial activity. 1,3,4-Oxadiazole derivatives (3a-c) were synthesized and were reported to exhibit notable corrosion inhibition in mild steel in acidic medium $\left(0.5 \mathrm{M} \mathrm{H}_{2} \mathrm{SO}_{4}\right)^{19}$. Similarly, ${ }^{20}$ oxadiazole derivative (4) mitigated corrosion of carbon steel in $1 \mathrm{M} \mathrm{HCl}$ as the acidic medium.
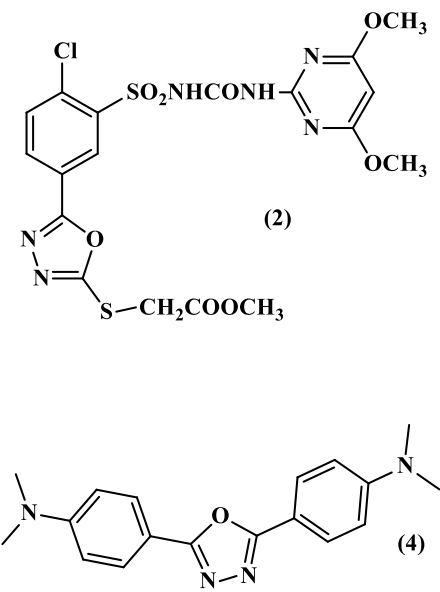

Figure 1. Oxadiazole derivatives with possible medicinal, agricultural and industrial applications<smiles>CC(C)(C)c1ccc(-c2nnc(-c3ccc(-c4ccccc4)cc3)o2)cc1</smiles><smiles>CCc1c(OC)nc2nc(-c3noc(C)n3)cn2c1C</smiles>

Fasiplon<smiles>C=C(NC(C)(C)c1nc(C(=O)NCc2ccc(F)cc2)c(O)c(=O)n1C)c1nnc(C)o1</smiles>

raltegravir<smiles>Cc1cc(CCCOc2c(C)cc(-c3noc(C(F)(F)F)n3)cc2C)on1</smiles>

Pleconaril<smiles>CCCCC(CCCC)CCCc1nc(-c2ccccc2)no1</smiles>

Butalamine<smiles>COc1nc(C)cnc1CS(=O)(=O)c1cccnc1-c1ccc(-c2nnco2)cc1</smiles>

Zibotentan

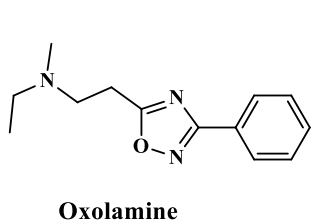

Oxolamine<smiles>Nc1nnc(C(=Cc2ccc([N+](=O)[O-])o2)c2ccco2)o1</smiles><smiles>COc1ccccc1N1CCN(CC(O)COc2cccc(-c3nnc(C)o3)c2)CC1</smiles>

Figure 2. Commercially available drugs containing oxadiazole scaffold 


\section{Chemistry of Oxadiazoles}

First reported the synthesis of oxadiazole was carried out in 1884 by Tiemann and Kruger. They named the compound as furo[ab]diazoles due to their isosteric relation with furan. The oxadiazole was formed by the substitution of two methine groups by imine groups in furan ${ }^{21,22}$. The isomers of oxadiazoles are 1,2,3-, 1,2,4, 1,2,5-, and 1,3,4-oxadiazoles. However, 1,2,3-isomer is the least stable of the lot owing to the more stable ring-open diazo-keto tautomer with the ring tautomer only found in benzo-fused solutions and in sydnone moieties as mesoionic compounds ${ }^{23}$.

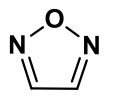

1,2,5-oxadiazole

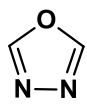

1,3,4-oxadiazole

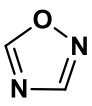

1,2,4-oxadiazole

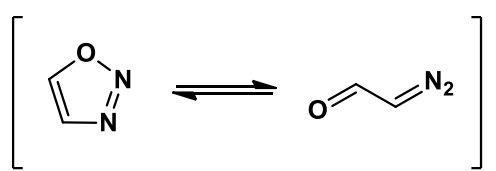

1,2,3-oxadiazole and its tautomer

Figure 3. Structures of the isomeric forms of oxadiazole

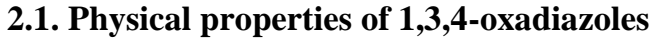

1,3,4-Oxadiazole is liquid with the boiling point of about $150^{\circ} \mathrm{C}$ (Table 1), having a restricted rotation with the three heteroatoms being able to form hydrogen bonds. Its 2,5-disubstituted derivatives are colourless. Characterization using infra-red (IR) has shown the predicted absorption of $\mathrm{C}=\mathrm{N}$ at $1640-1650 \mathrm{~cm}^{-1}$ and $\mathrm{C}-\mathrm{O}$ at $1020 \mathrm{~cm}^{-1}$. According to NMR data, the chemically equivalent protons showed a peak at
$8.73 \mathrm{ppm}$ in $\mathrm{CDCl}_{3}{ }^{23}$. Molecular ion peak was reported as the most stable peak based on Mass spectra analysis. $1,3,4$-Oxadiazole is an aromatic molecule that is symmetric, having resonance energy of $167.4 \mathrm{~kJ} / \mathrm{mol}$.

The refractive index $\mathrm{nD}$ of 1,3,4-oxadiazole is 1.43. Its solubility in aqueous solutions depended on the nature of substituent attached. Hence, 2,5-dimethyl substituted compound is soluble in water, while the 2,5-diphenyl substituted counterpart is less soluble as expected

Table 1: The physical properties of 1,3,4-oxadiazole

\begin{tabular}{|c|c|}
\hline Property & Information \\
\hline Molecular weight & $70.051 \mathrm{~g} / \mathrm{mol}$ \\
\hline Molecular formula & $\mathrm{C}_{2} \mathrm{H}_{2} \mathrm{~N}_{2} \mathrm{O}$ \\
\hline Density & $1.2 \mathrm{~g} / \mathrm{cm}^{3}$ \\
\hline Melting point & $-4.26^{\circ} \mathrm{C}$ \\
\hline Boiling point & $150^{\circ} \mathrm{C}$ \\
\hline Flashpoint & $62.4^{\circ} \mathrm{C}$ \\
\hline Vapour pressure at $25^{\circ} \mathrm{C}$ & $5.0 \mathrm{mmHg}$ \\
\hline Enthalpy of vaporization & $31.1 \mathrm{~kJ} / \mathrm{mol}$ \\
\hline Index of refraction & 1.416 \\
\hline Predicted Molar refractivity (ACD/Labs Percepta \\
Platform)
\end{tabular}

\subsection{Reactions of 1,3,4-oxadiazoles}

Studies have confirmed increasing aromaticity in 1,3,4-oxadiazole over 1,2,4-oxadiazole most likely due to its symmetrical structure leading to a reduction in the electrophilicity of 1,3,4- oxadiazole ${ }^{23}$. Hence, 1,3,4-oxadiazole favored substitution reactions over addition reactions as envisaged in aromatic compounds. The 1,3,4-oxadiazoles undergo the following reactions:

\subsubsection{Rearrangement reactions}

1,3,4-oxadiazoles can undergo rearrangement reactions in the presence of bases ${ }^{24}$. Almasirad and colleagues reported the transformation of 1,3,4-oxadiazole to 1,3,4-triazole in the presence of potassium hydroxide ${ }^{25}$. Similarly, the same conversion was done in the presence of amines (2-methoxyphenylamine and 2-methoxybenzylamine) and hydrazine hydrate 26,27. The rearrangement reaction followed a route that substituted the oxygen in position 1 with a nitrogen atom. It proceeded via ring cleavage forming an acyclic intermediate before the formation of the triazole. 
<smiles>CCOc1nnc(-c2ccccc2Oc2ccccc2F)[nH]1</smiles><smiles>Cc1ccc(OCc2n[nH]c(=S)o2)c(C(=O)c2cccc(Cl)c2)c1</smiles>

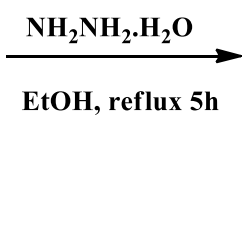<smiles>Cc1ccc(OCc2n[nH]c(=S)n2N)c(C(=O)c2cccc(Cl)c2)c1</smiles>

Scheme 1. Rearrangement reactions of 1,3,4-oxadiazoles

\subsubsection{Electrophilic attack at nitrogen}

1,3,4-Oxadiazoles are known as weak bases; this is as a result of the overall inductive effect of the heteroatoms in the ring. 1,3,4-oxadiazoles can undergo $\mathrm{N}$-alkylation reactions with alkyl halides, the product obtained in the alkylation of substituted 1,3,4-oxadiazole was endo- $N$ derivatives ${ }^{28}$.<smiles>CCc1nnc(NC(=O)C(F)(F)F)o1</smiles><smiles>CCc1nnc(NC(=O)C(F)(F)F)o1</smiles>

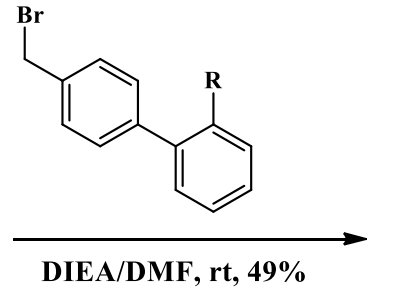

DIEA $=$ diisopropylethylamine $\mathbf{R}=($ N-triphenylmethyl)tetrazol-5-yl

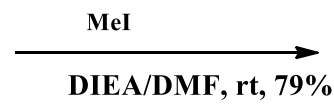<smiles>[R]c1ccccc1-c1ccc(Cn2nc(CC)o/c2=N\C(=O)C(F)(F)F)cc1</smiles><smiles></smiles>

Scheme 2. Electrophilic addition of alkyl substituents on the nitrogen

\subsubsection{Nucleophilic attack at carbon}

Nucleophiles attack the carbon atoms of 1,3,4-oxadiazoles. This was one of the key reactions of the scaffold when treated with strong bases. Monosubstituted oxadiazoles were alkylated before the deprotonation of the free ring methine carbon atom ${ }^{29,30}$. 


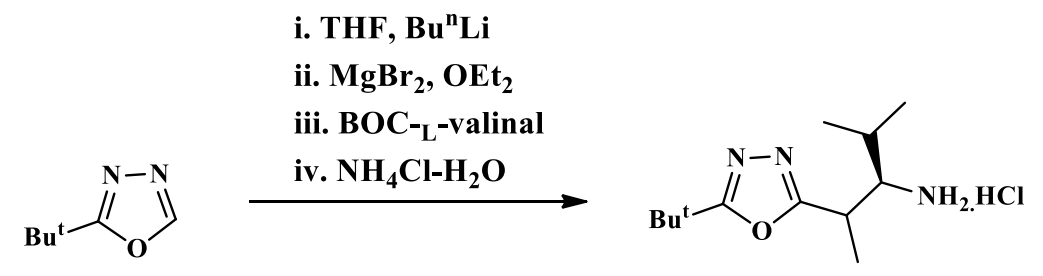

BOC $_{-}-$-valinal = tert-butyl-N-[(1S)-1-(methylethyl)-2-oxoethyl]carbamate

Scheme 3. Nucleophilic addition on monosubstituted 1,3,4-oxadiazoles

Furthermore, disubstituted 1,3,4-oxadiazole such as 2-methyl-5-phenyl-1,3,5-oxadiazole was treated with butyllithium in the presence and absence of an alkylating agent, with the lithium derivative being readily alkylated to (6) in the former. The latter led to the formation of a dimer followed by ring-opening to give the corresponding $N$-benzoylated hydrazone (5) and as shown in Scheme ${ }^{29}$.
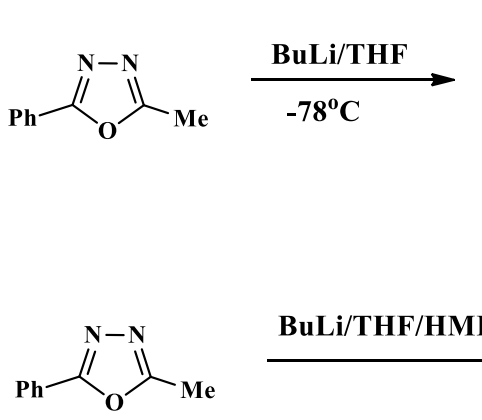<smiles>C=C1OC(c2ccccc2)=NN1[AlH2]</smiles>

(1)
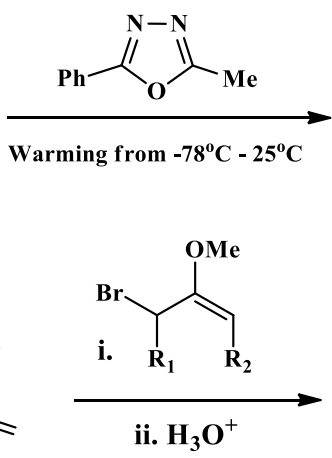<smiles>C/C(Cc1nnc(-c2ccccc2)o1)=N/NC(=O)c1ccccc1</smiles>

(5)<smiles>[R2]C(=O)C([R1])Cc1nnc(-c2ccccc2)o1</smiles>

(6)

$$
\mathbf{R}_{\mathbf{1}}=\mathbf{R}_{\mathbf{2}}=\mathbf{H} ; \mathbf{R}_{\mathbf{1}}=\mathbf{R}_{\mathbf{2}}=\left(\mathrm{CH}_{\mathbf{2}}\right)_{\mathbf{4}}
$$

Scheme 4. Substitution reactions of disubstituted 1,3,4-oxadiazoles

\subsubsection{Phosphorylation of 1,3,4-oxadiazole}

1,3,4-Oxadiazoles underwent phosphorylation with phosphorus (III) halides in the presence of a base. The phosphorylation of 2-phenyl-1,3,4-oxadiazole was carried out in phosphorus (III) chloride using triethylamine as a base. The two derivatives formed in a ratio of $1: 0.25$ at $-40^{\circ} \mathrm{C}$ were dichlorophosphine (II) (7) and chlorophosphine (III) (8) respectively, regardless of the amount of phosphorus trichloride used.
Improvement of the product yield was obtained when the reaction was carried out at room temperature, provided a much better ratio of 1:0.6 was used.

2-Phenyl-1,3,4-oxadiazole reacted with chlorodi phenylphosphine and dichlorophenylphosphine which was less reactive than the phosphorus (III) halides for 24 hours to give phosphines (9) and (10) ${ }^{31}$. 


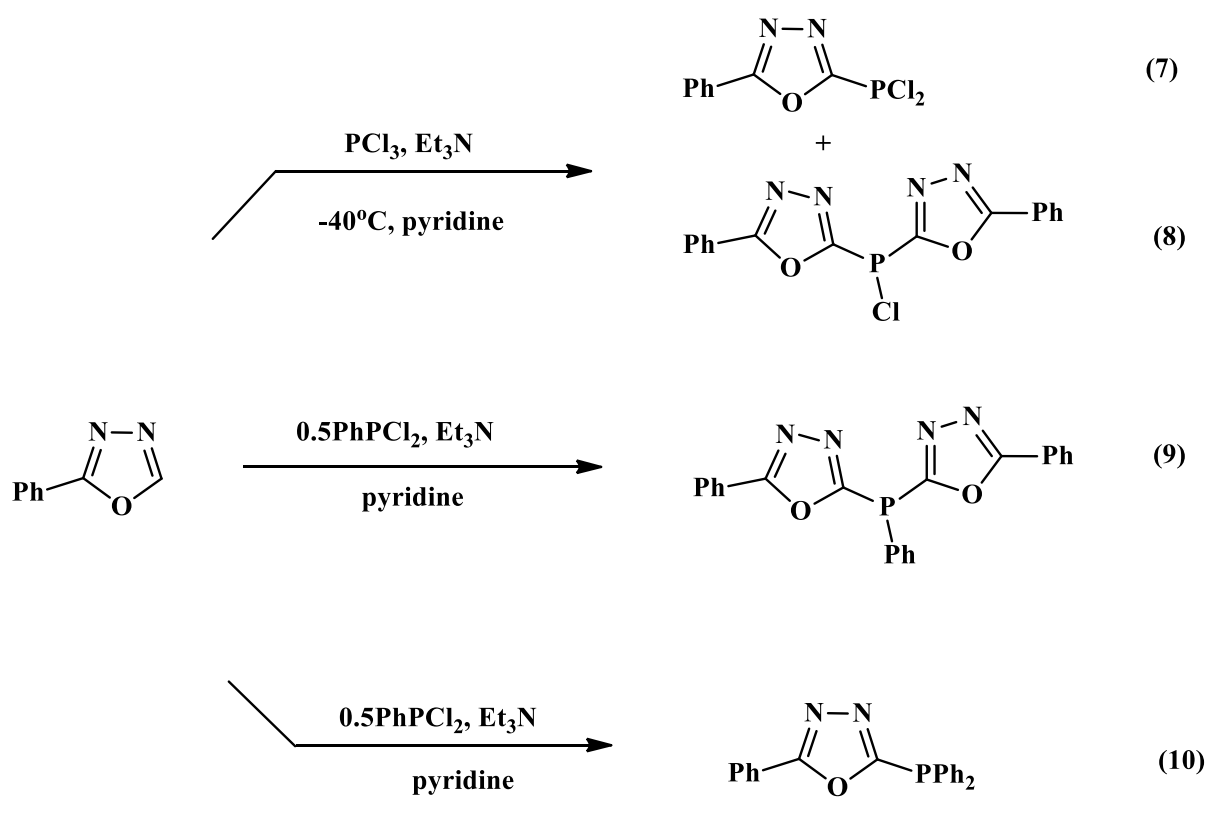

Scheme 5. Phosphorylation of 1,3,4-oxadiazole

\subsection{Recent synthesis of 1,3,4-oxadiazole}

2.3.1. Cyclization of hydrazides using carbon disulphide $\left(\mathbf{C S}_{2}\right)$

Annulation of hydrazides on carbon disulphide in the presence of a base was reported to give high yields. The synthesis of various 5-(aryl)-1,3,4-oxadiazole-2-thiol using hydrazides as the precursor was recently carried out by Caneschi and colleagues, as shown in Scheme 6 .
This synthetic pathway led to the formation of a thiol group in position 2 of the oxadiazole ring $\mathbf{1 1}^{11}$. The hydrazide was obtained from the hydrazinolysis of the ester, initially produced from esterification of benzoic acid using reaction condition i. Following a similar route, coumarin-based 1,3,4-oxadiazole was synthesized in $76 \%$ yield after heating under reflux for $12 \mathrm{~h}^{32}$.

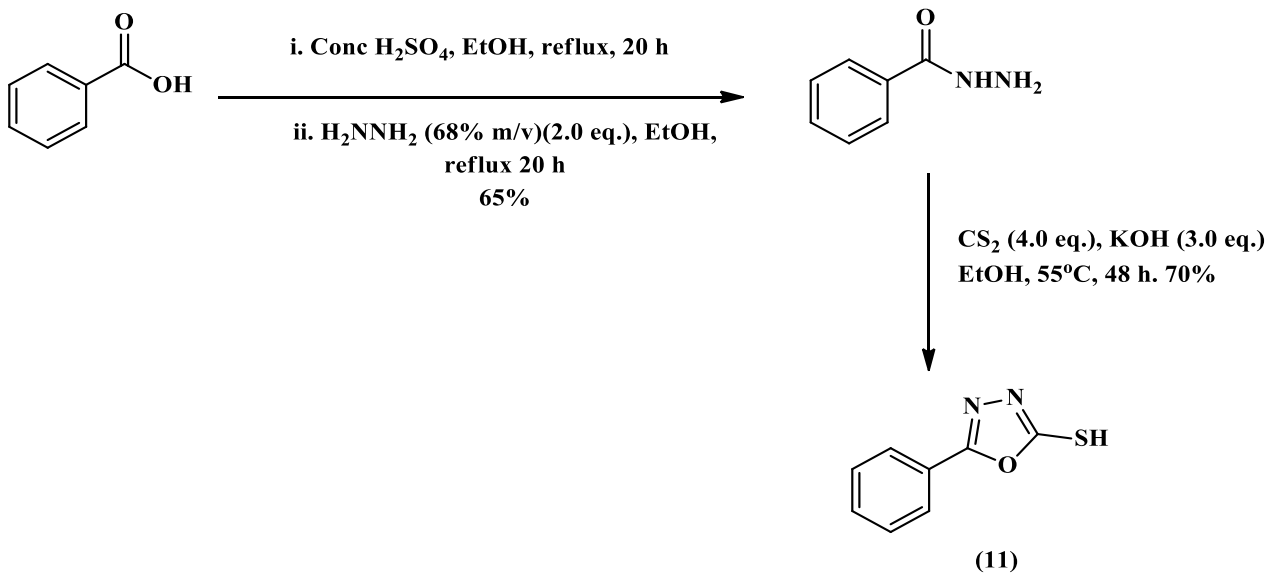

Scheme 6. Cyclization of hydrazide to 1,3,4-oxadiazole using carbon disulphide $\left(\mathrm{CS}_{2}\right)$<smiles>Cc1cc(=O)oc2cc(OCC(=O)NN)ccc12</smiles>

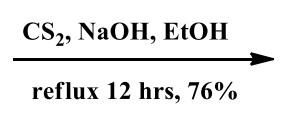<smiles>Cc1cc(=O)oc2cc(OCc3nnc(S)o3)ccc12</smiles>

Scheme 7. Synthesis of 1,3,4-oxadiazole coupled to coumarin using $\mathrm{CS}_{2}$ 
Song and colleagues also reported the synthesis of 1,3,4-oxadiazole derivatives by cyclizing the hydrazide intermediate 12 with $\mathrm{CS}_{2}$ using potassium hydroxide
$(\mathrm{KOH})$ as the base as shown below with high yields ranging from $86.2-98.6 \%^{12}$.
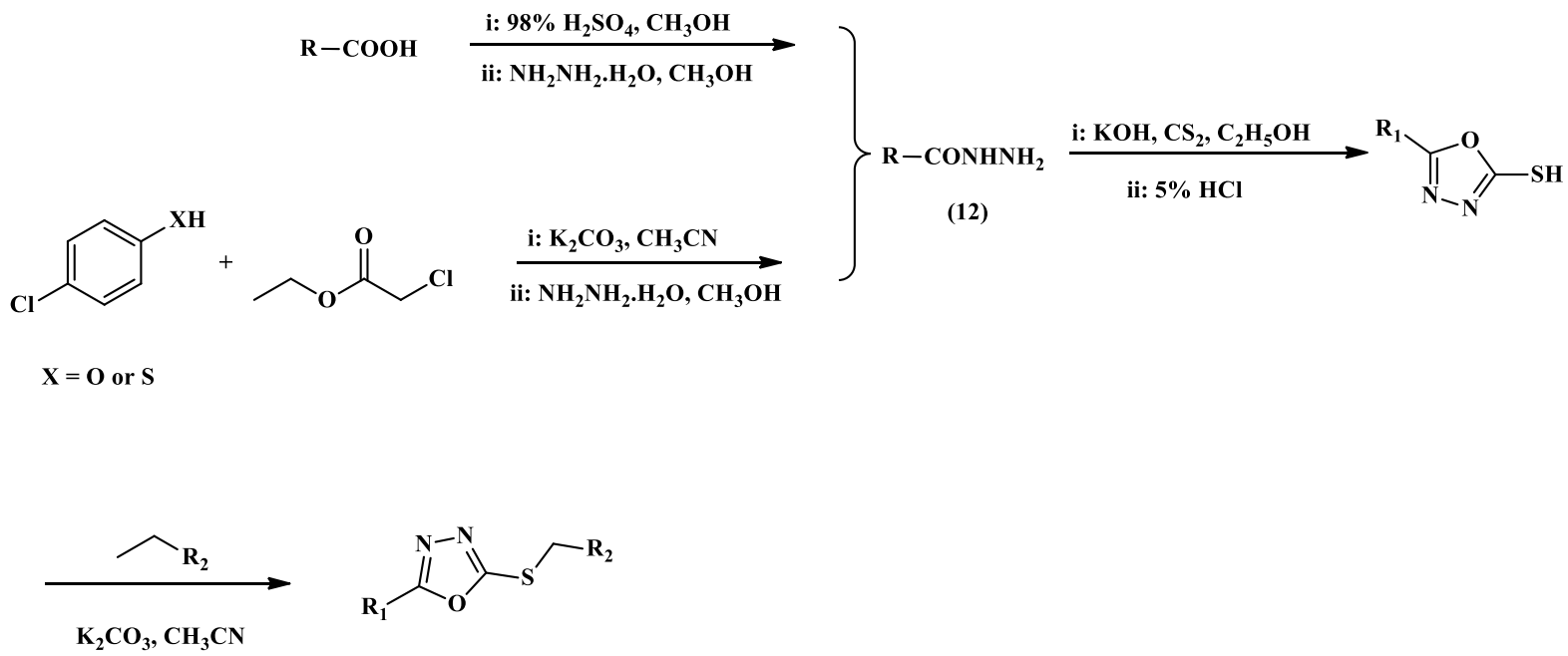

Scheme 8. Cyclization to form 1,3,4-oxadiazole using $\mathrm{CS}_{2}$ by Song and co-workers

2.3.2. Condensation of aldehydes with hydrazides

One step condensation reaction between aldehydes and hydrazides using glacial acetic acid, followed by
chloramine-T had successfully produced 1,3,4-oxadiazoles (57) in moderate to high yields as shown by Scheme $9^{33}$.<smiles>NNC(=O)Nc1ccncc1</smiles>

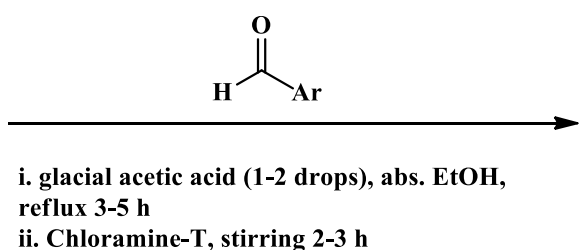

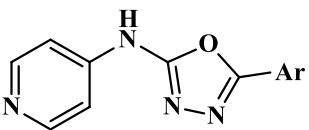

(13)

Ar: Various substituted aromatic aldehydes

Scheme 9. One step condensation between aldehydes and hydrazides to form oxadiazole

\subsubsection{Condensation of hydrazides with halide} substituted acetic acids using $\mathrm{POCl}_{3}$

The refluxing of hydrazides with substituted haloacetic acids using phosphorus oxychloride as cyclization agent yielded the respective 1,3,4-oxadiazoles. Lakshmithendral and coworkers followed this pathway in the synthesis of 2,5-disubstituted 1,3,4-oxadiazole derivatives (14) as shown in Scheme $10^{34}$.
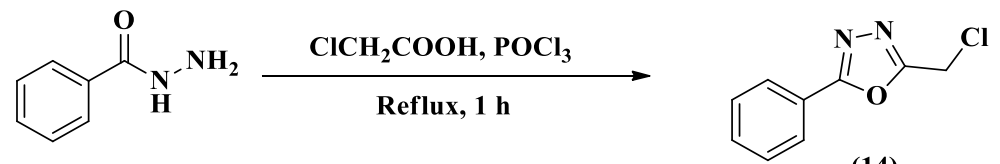

(14)

Scheme 10. Condensation of hydrazide with 2-chloroacetic acid to give 1,3,4-oxadiazole

Similarly, using $\mathrm{POCl}_{3}$ as the cyclo-dehydrating agent, various hydrazides were condensed with $\beta$-benzoyl propionic acid giving the corresponding 2,5disubstituted products (15) in high yields (78-90\%) ${ }^{35}$. 


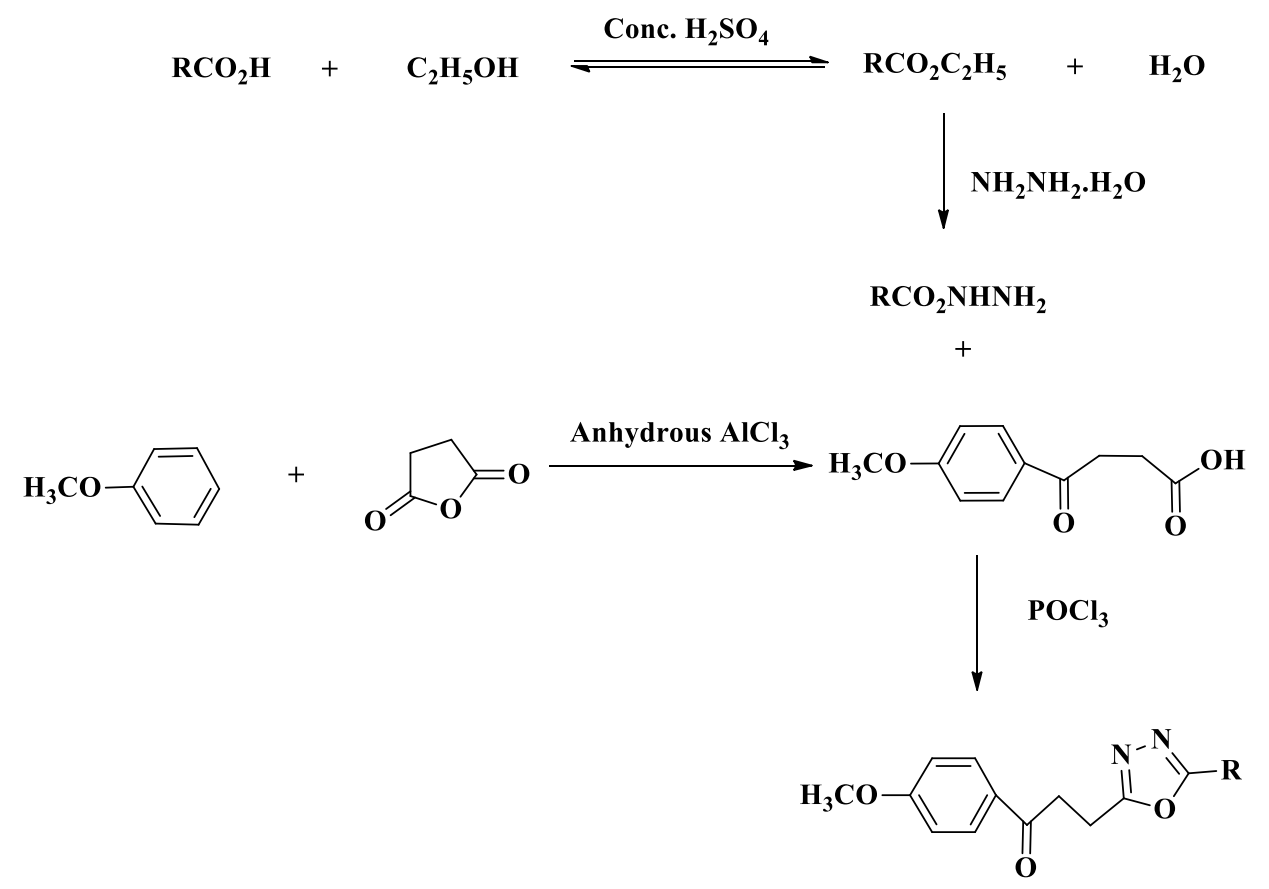

(15)

Scheme 11. Condensation of hydrazides with $\beta$-benzoyl propionic acid to give 2,5-disubstituted-1,3,4-oxadiazoles

2.3.4. Cyclization of hydrazides via oxidative cleavage of $\mathrm{C}(\mathrm{CO})-\mathrm{C}($ methyl) bond of methyl ketones

The direct cyclization of hydrazides with methyl ketone to form 1,3,4-oxadiazole via the cleavage of the acylcarbon bond in the methyl ketone using different bases for optimization study was explored by Gao and coworkers ${ }^{36}$. The reaction was proposed to start from the cleavage of the $\alpha$-hydrogen on the methyl group followed by cyclization and diacylation of the methyl ketone (16).

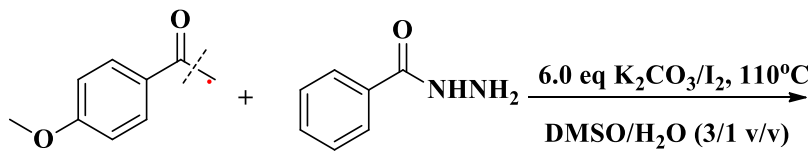

(16)

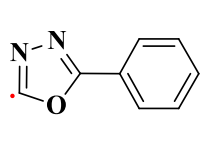

(17)

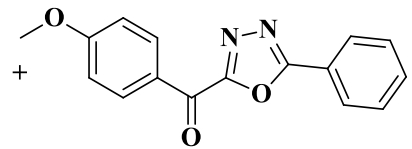

(18)

Scheme 12. Oxidative cleavage of $\mathrm{C}(\mathrm{CO})-\mathrm{C}$ (methyl) bond of methyl ketones to yield oxadiazole

The optimal condition reported for the synthesis of (18) involved using 6.0 eq $\mathrm{K}_{2} \mathrm{CO}_{3}$ and $2.5 \mathrm{eq}$ of $\mathrm{I}_{2}$ at $110^{\circ} \mathrm{C}$ for $16 \mathrm{~h}$. One-step reaction in $\mathrm{DMSO} / \mathrm{H}_{2} \mathrm{O}$ (3:1) led to the decarboxylation of compound (18) to produce compound (17) in $93 \%$ yield and zero yield for (18). Using 2.5 eq of $\mathrm{I}_{2}$ in 3 eq of $\mathrm{K}_{3} \mathrm{PO}_{4}$ in DMSO gave a yield of $10 \%$ for (17) and $89 \%$ for (18). Using the optimized condition for the de-acylation of (18) to (17) various hetero(aryl) methyl ketone and aryl hydrazides were also used in the reaction route giving moderate to high yields (Scheme 12).
A similar iodine-mediated domino oxidative cyclization of substituted styrene or phenylacetylene was reported. The reaction proceeded via the oxidative cleavage of the $\mathrm{C}\left(\mathrm{sp}^{2}\right)-\mathrm{H}$ or $\mathrm{C}(\mathrm{sp})-\mathrm{H}$ bond, also following the cyclization-deacylation route. $\mathrm{K}_{2} \mathrm{CO}_{3}$ was found to be an excellent base being more functional than the tested $\mathrm{NaHCO}_{3}, \mathrm{MeOH}, t-\mathrm{BuOK}, \mathrm{K}_{3} \mathrm{PO}_{4}$ and $\mathrm{Cs}_{2} \mathrm{CO}_{3}$, using DMSO as a solvent. Optimal conditions included the use of $\mathrm{O}_{2}$ (1atm), 2.5 equiv of iodine and 6.0 equiv of the base at $120^{\circ} \mathrm{C}$ for $6 \mathrm{~h}$. The reaction route gave moderate to high yields for various acyl hydrazides and styrene/phenyl acetylene derivatives $(35-86 \%)^{37}$. 


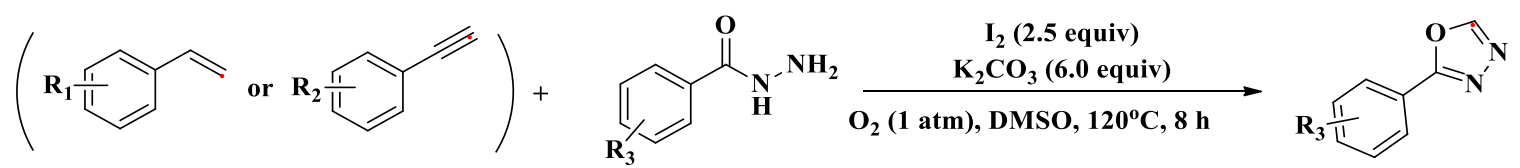

Scheme 13. Oxidative cleavage of the $\mathrm{C}\left(\mathrm{sp}^{2}\right)-\mathrm{H}$ or $\mathrm{C}(\mathrm{sp})-\mathrm{H}$ bond leading to the formation of 1,3,4-oxadiazole

\subsubsection{Cyclocondensation of hydrazides with triethyl orthoesters}

Kudelko and coworkers explored the cyclocondensation of $\alpha, \beta$-unsaturated hydrazide route using triethyl orthoesters. The starting material used was heteroatomic aldehydes such as 3-pyridine carboxaldehyde (19), which was converted into $\alpha, \beta$-unsaturated carboxylic acid using malonic acid refluxed in pyridine and piperidine as a catalyst. The formed acid was converted to its corresponding salt when treated with potassium hydroxide. It was subsequently treated with ethyl chloroformate and then hydrazine hydrate in one pot to form the hydrazide. Finally, the hydrazide formed in good yield was treated with triethyl orthoesters in glacial acetic acid to yield the desired 1,3,4-oxadiazole (20) as shown in Scheme $14^{38}$.

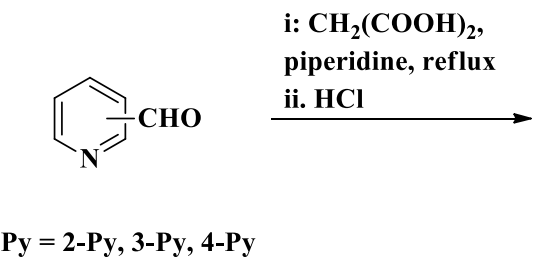

(19)

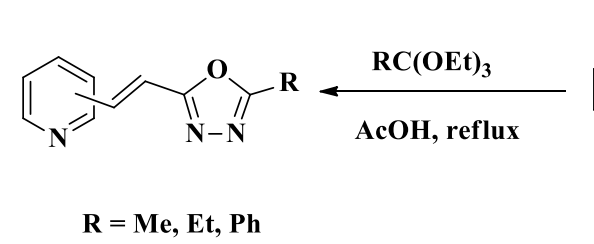

(20)

Scheme 14. Cyclocondensation of hydrazides with triethyl orthoesters

It was reported that an increase in the bulkiness of the R-group led to increasing yield, as the yield was higher when $\mathrm{R}=\mathrm{Ph}$. This could be explained as a result of extended conjugation gained an increase in the boiling point of the resulting triethyl orthoester.

\subsubsection{Hypervalent iodine( $V$ ) mediated synthesis of 2-substituted-1,3,4-oxadiazoles}

This one-pot synthetic route for 1,3,4-oxadiazole was explored by Prabhu and Sureshbabu. The hydrazide was

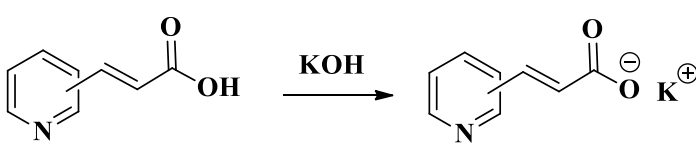

CICOOEt

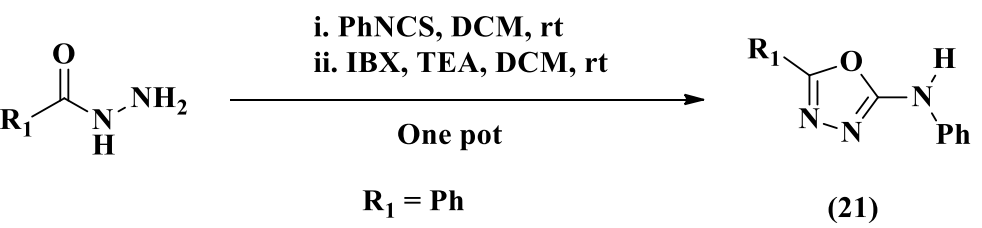

Scheme 15: Hypervalent iodine(V) mediated synthesis of 1,3,4-oxadiazoles

\subsubsection{Pd-catalyzed cyclo-condensation between hydrazides and isocyanides}

treated with phenylisothiocyanate in DCM at room temperature. After the completion of the reaction which was monitored by TLC, the expected, resulting $N$ acylthiosemicarbazide was treated in-situ with 2 eq. of triethylamine (TEA) and 2-Iodoxybenzoic acid (IBX) as the oxidizing agent. The reacting mixture was stirred for 15 mins, and the 2-amino-1,3,4-oxadiazole (21) was formed in high yield of $92 \%{ }^{39}$.
Oxidative annulation to 1,3,4-oxadiazoles from hydrazides and isocyanides was optimized using 
atmospheric oxygen as oxidant in toluene. It was catalyzed with $5 \mathrm{~mol} \%$ of Palladium (II) acetate at $80^{\circ} \mathrm{C}$ to afford the product in excellent yield as high as $94 \%$ recorded ${ }^{40}$.

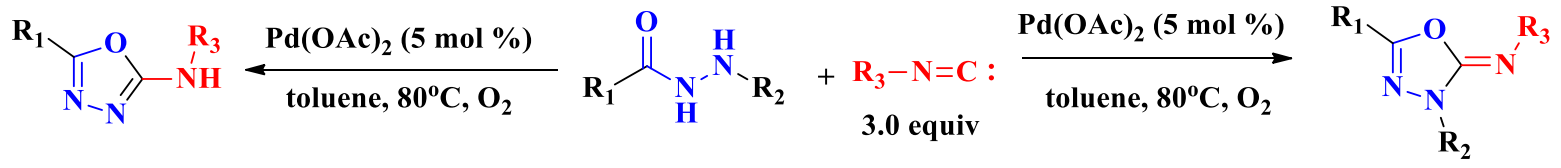

$$
\begin{aligned}
& \mathbf{R}_{\mathbf{2}}=\mathbf{H}, \mathbf{A c} \\
& \mathbf{R}_{\mathbf{2}}=\text { alkyl, aryl }
\end{aligned}
$$

Scheme 16. Pd-catalyzed condensation between hydrazides and isocyanides

\subsubsection{Camphorsulfonic acid catalyzed one-pot} synthesis of 1,3,4-oxadiazoles

Mule and colleagues reported the facile one-pot synthesis of 2,5-disubstituted-1,3,4-oxadizole from acyl hydrazides and acyl chloride using 10-Camphorsulfonic acid. Optimization screening carried out, revealed that the presence of $( \pm)$-CSA led to the generation of the oxadiazole with highest yields, much higher than that gotten from other reagents such as $\mathrm{POCl}_{3}, \mathrm{SOCl}_{2}$, Burgess reagents and others ${ }^{41}$.<smiles>CCOc1cccc(C(=O)NN)c1</smiles>

Scheme 17. 10-Camphorsulfonic acid catalyzed one-pot synthesis of 1,3,4-oxadiazole

The reaction was adapted for the synthesis of chromene substituted 1,3,4-oxadiazole, from chromene acid hydrazide and various acyl chlorides.

\subsubsection{Oxidative cyclization of Hydrazones} a. Cyclization of hydrazones using Iodobenzene 1,3,4-oxadiazoles had been synthesized from hydrazones precursors, which in turn were synthesized in the reaction between hydrazides and carbonyls (aldehydes). Yu and co-workers synthesized new series of 1,3,4-oxadiazole derivatives (22) through the cyclization of hydrazones using Iodobenzene dichloride as an oxidative agent at moderate temperatures between $35-40{ }^{\circ} \mathrm{C}^{42}$.

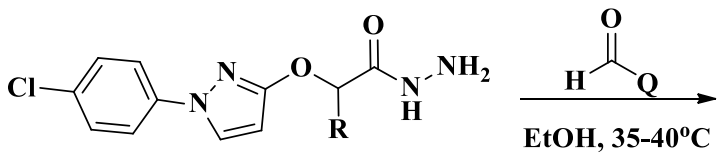<smiles>[R]C(Oc1ccn(-c2ccc(Cl)cc2)n1)C(=O)N/N=C/O</smiles>

$$
\begin{aligned}
& \mathrm{R}=\mathrm{H} ; \mathrm{CH}_{3} \\
& \mathrm{Q}=\text { alkyl; aryl; heteroaryl group }
\end{aligned}
$$

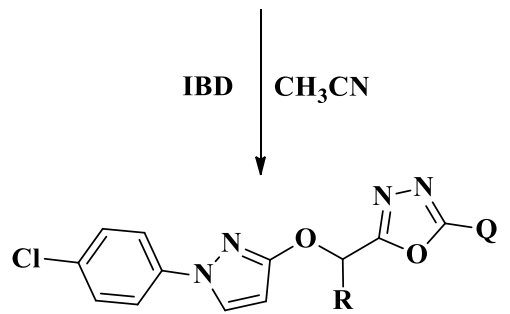

(22)

Scheme 18. Cyclization of hydrazone using IBD to obtain 1,3,4-oxadiazole

b. Cyclization of hydrazones using acetic anhydride Koçyiğit-Kaymakçığlu and coworkers synthesized a library of biologically active oxadiazole from hydrazone intermediate. The intermediate was derived from the treatment of hydrazides with various aromatic aldehydes. The formed hydrazone was cyclized using acetic anhydride to 1,3,4-oxadiazole (23a-g) having an acetal group at the $N-3$ position with moderate to high yields (49-90\%) ${ }^{43}$. 


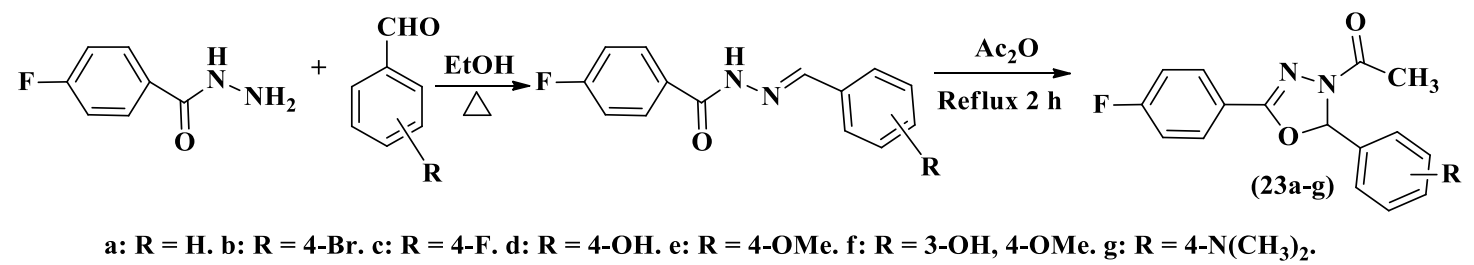

Scheme 19. Cyclization of hydrazones using acetic anhydride

\section{c. Cross dehydrogenative coupling having hydrazone intermediate}

The catalytic cross dehydrogenative coupling of hydrazides which follows hydrazone intermediate before the product was done using $\mathrm{CuBr}$ as a catalyst. No reaction took place without the introduction of the catalyst. For optimal conditions, the reaction was best carried out using tert-butyl hydroperoxide (TBHP) as an oxidant in acetonitrile with the addition of sulphuric acid, as shown in Scheme 20. The reaction proceeded via the oxidation of the $\mathrm{sp}^{3} \mathrm{C}-\mathrm{H}$ bonds in the $N$-alkylhydrazides ${ }^{44}$.

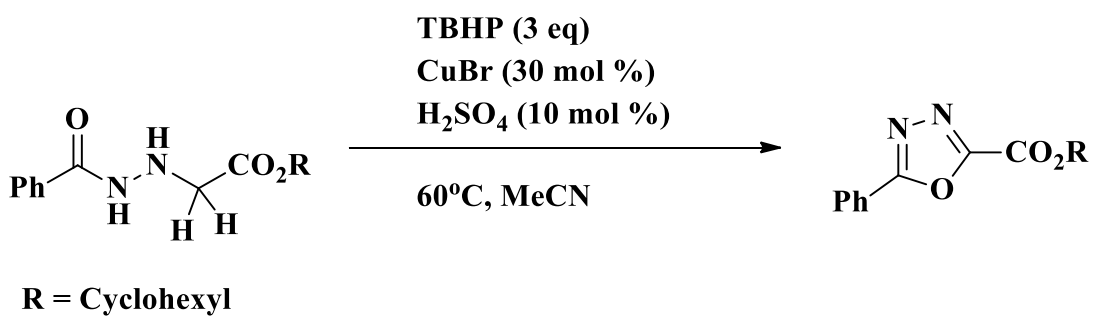

Scheme 20. CuBr catalyzed synthesis of 1,3,4-oxadiazole having hydrazone intermediates.

\section{d. Iron (III)/TEMPO-catalyzed cyclization of hydrazones}

2,5-Disubstituted 1,3,4-oxadiazoles synthesis was studied using $\mathrm{Fe}^{3+} / \mathrm{TEMPO}$ as a catalyst in the oxidative annulation of aroyl hydrazones. After numerous tests were carried out in various conditions. Optimal conditions gave yield as high as $97 \%$, which involved the use of aqueous iron (III) nitrate as the iron salt. Other iron salts tested gave very low to no products at all. TEMPO with dichloromethane was used as the solvent and Magnesium sulphate as an additive in the presence of oxygen at $35^{\circ} \mathrm{C}$ for $6 \mathrm{hr} .{ }^{45}$.
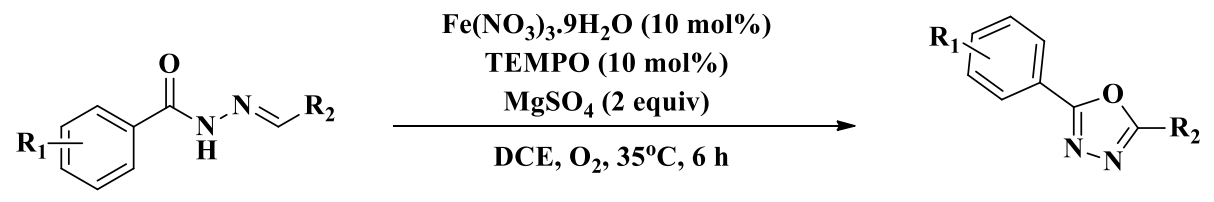

Scheme 21. Iron (III)/TEMP-catalyzed cyclization of hydrazones

\section{e. Iodine-catalyzed oxidative cyclization of} acylhydrazine

Majji and coworkers carried out the oxidative annulation of arylacylhydrazone yielding the corresponding 1,3,4-oxadiazole (24). Optimum conditions were achieved using $\mathrm{H}_{2} \mathrm{O}_{2}$ as oxidant and
$\mathrm{K}_{2} \mathrm{CO}_{3}$ as a base in DMSO. Good to excellent yields ranging from $60-92 \%$ were obtained. No reaction took place using acylhydrazones gotten from aliphatic aldehyde and aliphatic hydrazide (i.e. $\mathrm{R}_{1}$ and $\mathrm{R}_{2}$ were aromatic) ${ }^{46}$.<smiles>[R]CN=NC([R1])=O</smiles>

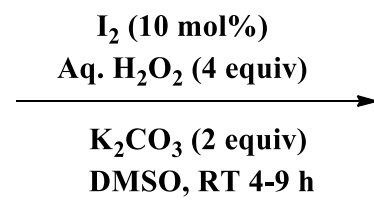

DMSO, RT 4-9 h<smiles>[R]c1nnc([R1])o1</smiles>

(24)

Scheme 22. Iodine-catalyzed oxidative cyclization of hydrazones 


\section{f. Cyclization of hydrazones in the presence of} bromine

The direct cyclization of hydrazones using glacial acetic acid and sodium acetate in the presence of bromine has been reported to yield 1,3,4-oxadiazole derivatives $\mathbf{( 2 5 )}$ in good yields ${ }^{35}$<smiles>[R]C=NNC(=O)c1ccccc1C(=O)c1ccccc1</smiles>

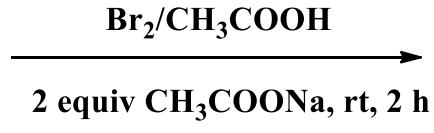<smiles>[R]c1nnc(-c2ccccc2C(=O)c2ccccc2)o1</smiles>

(25)

Scheme 23. Bromine catalyzed cyclization of hydrazones

2.3.10. Desulfurization synthetic approach a. Annulation and desulfurization of thiosemicarbazide

Desulfurization of thiosemicarbazide is a reagent-based regioselective cyclization to 1,3,4-oxadiazole. Depending on the reagent used, the cyclization can either result in the formation of 1,3,4-oxadiazole (26) or 1,3,4-thiadiazole (27) derivatives. Yang and coworkers carried out the desulphurization of acylthiosemicarbazide formed from treating isothiocyanates with acylhydrazides in the presence of TEA at room temperature. It was then annulated using $\mathrm{EDC} . \mathrm{HCl}$, in DMSO at $60^{\circ} \mathrm{C}$ for $2 \mathrm{~h}$<smiles>[R]C(=O)NN</smiles><smiles>[R1]NC(=S)NNC([R2])=O</smiles><smiles>CCCC</smiles><smiles>[R]Nc1nnc([R2])o1</smiles><smiles>[R2]c1nnc(N([R3])[Z])s1</smiles><smiles>[R]Nc1nnc([R2])s1</smiles><smiles>[R2]c1nnc(N([R3])[R])o1</smiles>

(27)

Reactions conditions: (a) triethylamine, THF, rt, 16 h. (b) EDC.HCl, DMSO, $60^{\circ} \mathrm{C}, 2 \mathrm{~h}$ (c) p-TsCl, TEA, NMP, rt, 2h. (d) Electrophiles, NaH, NMP, rt, 8 h. (e) Electrophiles, NaH, THF, rt, 1 h

Scheme 24. Cyclodesulphurization of thiosemicarbazide to 1,3,4-oxadiazoles

Optimization studies were carried out varying the solvent, bases, and substituents $\left(\mathrm{R}_{1}\right.$ and $\left.\mathrm{R}_{2}\right)$. The findings revealed that when $\mathrm{EDC} . \mathrm{HCl}$ was used in DMSO, the reaction was completely regioselective for the 1,3,4-oxadiazole derivatives regardless of the substituents, leading to yields as high as 99\%. Using $p$-TsCl as dehydrating/desulfurizing agents and bases such as t-BuOK and $\mathrm{NaOH}$, gave preference to the synthesis of 2-amino-1,3,4-oxadiazole with TEA shifting the reaction to produce the thiadiazole derivatives. Non-polar solvents showed higher regioselectivity for 1,3,4-oxadiazole and the polar solvents. It yielded the thiadiazole in such a way that $p$-TsCl/TEA in polar solvent such as $N$-methyl-2pyrrolidone (NMP) showed high regioselectivity of (4:96) in favor of the thiadiazole. Using electronwithdrawing $R_{1}$ as substituents led to the higher regioselectivity of the 1,3,4-oxadiazole even in NMP. High electron-withdrawing $\mathrm{R}_{2}$ substituents gave high regioselectivity of the thiadiazole substituents. The proposed mechanism for regioselective cyclization 
reaction in the presence of $\mathrm{p}$-TsCl/TEA in NMP was shown in Scheme $25^{47}$.

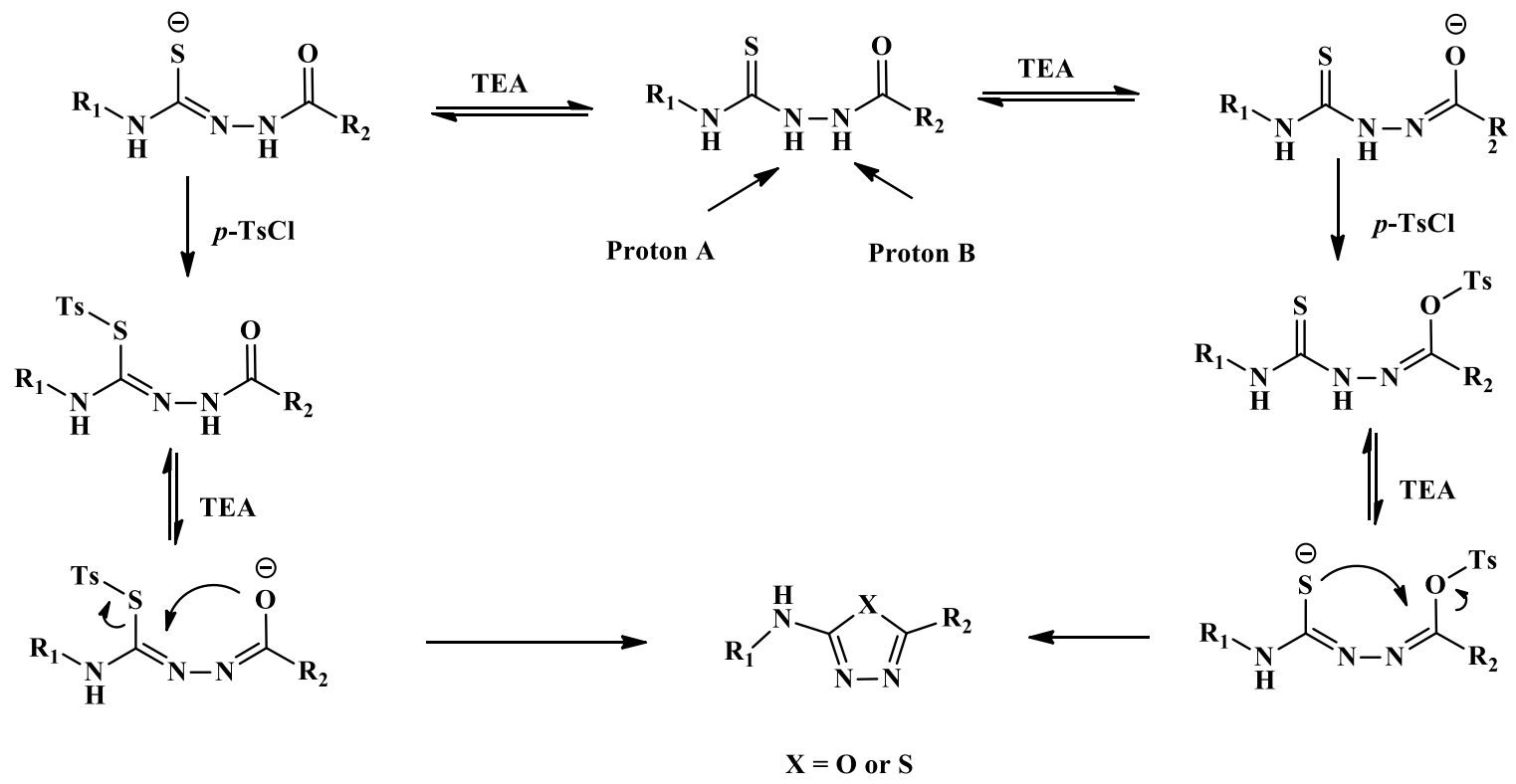

Scheme 25. Mechanism for the cyclodesulphurization/cyclodehydration of thiosemicarbazide

\section{b. Facile cyclodesulfurization using coupling reagents}

Maghari and coworkers carried out the cyclodesulfurization of thiosemicarbazides to obtain 1,3,4-oxadiazoles (28) using hydrazides and isothiocyanates as starting materials. The obtained thiosemicarbazides was desulfurized in the presence of coupling reagents to get the oxadiazole product in high yields. This method reduced the use of harsh reagents and conditions generally used in the synthesis of 1,3,4-oxadiazoles. Amongst all the coupling agents used, $\quad O$-(benzotriazole-1-yl)- $N, N, N^{\prime}, N^{\prime}$-tetramethyl uronium tetrafluoroborate (TBTU) was the most efficient. It gave a high yield of $85 \%$ in $12 \mathrm{hrs}$. This was even better than the use of alternative desulfurization agents under the same conditions such as $p$-TsCl/py, $\mathrm{Hg}(\mathrm{OAc})_{2}, \mathrm{Zn}(\mathrm{OAc})_{2}$ and $\mathrm{Cu}(\mathrm{OAc})_{2}{ }^{48}$.<smiles>COc1ccc(N(C)C)cc1</smiles><smiles>COc1ccc(NC(=S)NNC(=O)c2ccccc2)cc1</smiles><smiles>COc1ccc(Nc2nnc(-c3ccccc3)o2)cc1</smiles>

Scheme 26. Cyclodesulphurization of thiosemicarbazide using TBTU

\subsubsection{Solid phase supported synthesis}

Yang and coworkers synthesized 1,3,4-oxadiazole starting from 4-benzyloxy-2-methoxybenzylamine merrified resins which were converted to thioisocyanate terminated Merrifield resin using carbon disulphide and TEA and in the presence of tetrahydrofuran at $25^{\circ} \mathrm{C}$ for $18 \mathrm{~h}$. The reaction of the thioisocyanate with benzohydrazide and TEA in THF at room temperature for $16 \mathrm{~h}$ gave acylthiosemicarbazide (29). The acylthiosemi carbazide was annulated following a desulfurative cyclization giving the 2-amino substituted oxadiazole (30). Complete regioselectivity for the 1,3,4-oxadiazole instead of the thiodiazole was gotten when annulation of the thiosemicarbazide was carried out with EDC.HCl in DMSO instead of $p$-TsCl/TEA, which gave moderate to high regioselectivity depending on the electron-withdrawing/donating nature of the $\mathrm{R}_{1}$ group ${ }^{49}$. 


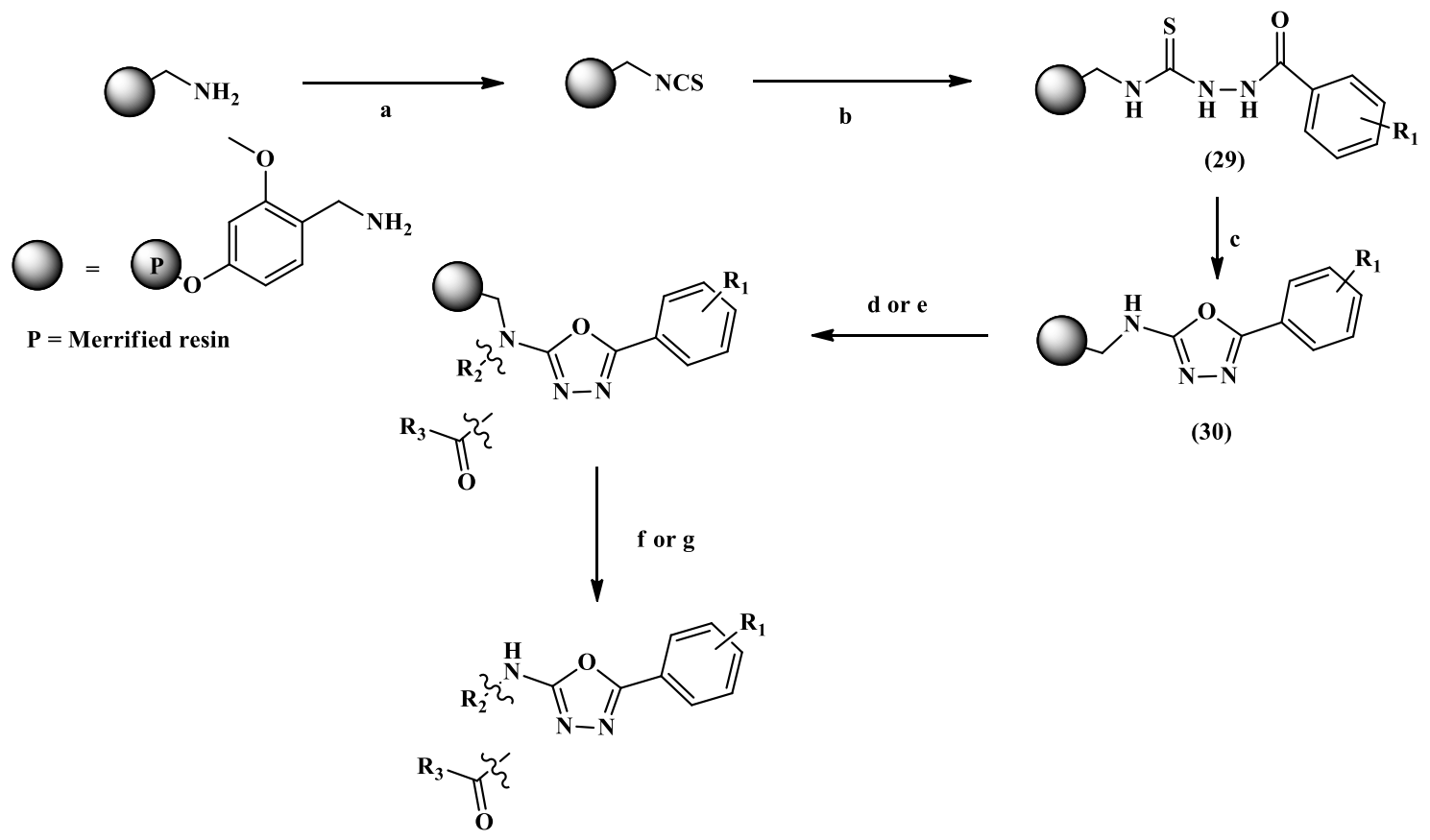

Reaction condition: (a) $\mathrm{CS}_{2}$, p-TsCl, TEA, THF, rt, $18 \mathrm{~h}$; (b) benzyhdrazide, TEA, THF, rt, 16 h (c) EDC.HCl, DMSO, $60^{\circ} \mathrm{C}, 16 \mathrm{~h}$; (d) alkyl halide, t-BuOK, DMF, $60^{\circ} \mathrm{C}, 16 \mathrm{~h}$; (e) acid chloride, pyridine, $60^{\circ} \mathrm{C}, 12 \mathrm{~h}$; (f) TFA/DCM $(1: 4 \mathrm{v} / \mathrm{v}), 40^{\circ} \mathrm{C}, 8 \mathrm{~h}$; (h) TFA/DCM (1:4, v/v), room temperature, $6 \mathrm{~h}$

Scheme 27. Solid-phase cyclodesulphurization of thiosemicarbazide

Following a similar route as Yang and co-workers, the desulfuration of hydrazinecarbothioamide resin (31) using $p$ - $\mathrm{TsCl}$ and pyridine in THF resulted in cyclization to the required 1,3,4-oxadiazole (32) as shown in Scheme $28{ }^{50}$.<smiles>[R]C(NCC)C(=O)NNC(=S)NCOCCNC(=O)C([2H])NCCO</smiles>

Scheme 28. Desulphurization of hydrazinecarbonthioamide resin

\subsubsection{Zinc catalyzed cyclization of} acyldithiocarbazates

Rahman and coworkers illustrated the synthesis of 1,3,4-oxadiazole from acyldithiocarbazates (33) using zinc as the catalyst. The reaction was a one-step route which involved the addition of $\mathrm{ZnCl}_{2}$ solution to compound (33) using $\mathrm{Et}_{3} \mathrm{~N}$ as base and THF as solvent. Excellent yields of $97 \%$ were recorded, and the catalytic effect of zinc was confirmed as the reaction did not proceed in the absence of zinc. Solvents such as dioxane with $\mathrm{KOH}$ as a base also gave a high yield of 1,3,4-oxadiazole (34) ${ }^{51}$. 


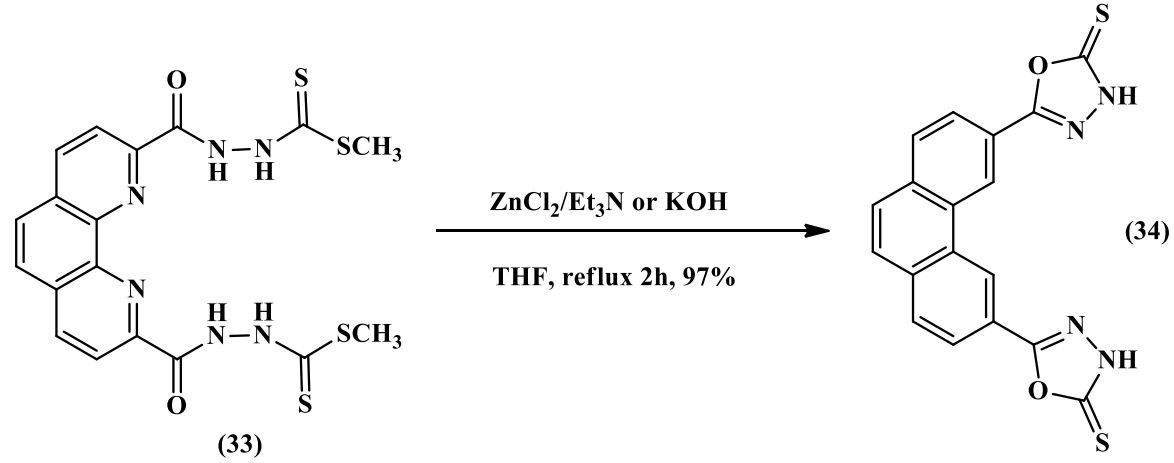

Scheme 29. Zinc catalyzed annulation of acyldithiocarbazates

2.3.13. Single-step cyclodeselenization of selenosemicarbazides

Treating the hydrazide (35) with isoseleocyanate (36) in $\mathrm{DMF}$ at $90^{\circ} \mathrm{C}$ for a time ranging from $3-8 \mathrm{hrs}$ depending on the substituents $\left(R_{1}\right.$ and $\left.R_{2}\right)$ gave the intermediate selenosemicarbazide (37) which was cyclodeselenized to form the required 1,3,4-oxadiazole (38) as shown in Scheme $30^{52}$.<smiles>[R]N=C=[Ni]</smiles>

(35)
(36)

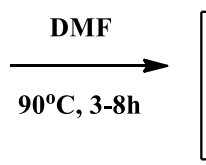<smiles>[R]NC(=[Se])NNC([R])=O</smiles>

(37)<smiles>[R]Cc1nnc([R2])o1</smiles>

(38)

Scheme 30. Cyclodeselenization of selenosemicarbazides in the absence of bases

Cyclodeselenization reaction to form 1,3,4-oxadiazole (39) had also been reported by Santhosh and coworkers, using molecular iodine. The reaction was at its optimum when THF was used as solvent and the mole ratio of $\mathrm{I}_{2}$ to TEA was $1: 2$. The reaction generated excellent yields, ranging from $89 \%$ to $94 \%{ }^{53}$.<smiles>[R]C(NP)C(=O)NN</smiles><smiles>[R]OC(=O)C([R1])N=C=[CH]</smiles>

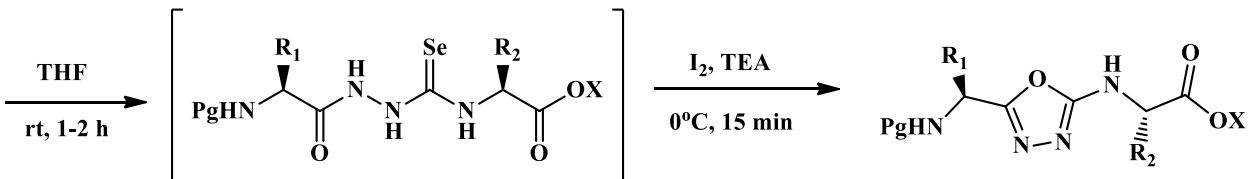

(39)

$\mathrm{Pg}=$ Boc or Cbz group

$X=$ Me or Et moiety

$\mathbf{R}_{1}, \mathbf{R}_{2}=$ amino acid side chain

Scheme 31. Cyclodeselenization of selenosemicarbazides in the presence of TEA

2.3.14. Ultrasound-assisted synthesis of 2 -aryl-1,3,4oxadiazole

Ultrasound-assisted synthesis was recognized as one of the green energy sources for organic synthesis. 1,3,4Oxadiazole (42) was synthesized speedily via sonification. A mixture of $N$-isocyanoimino triphenyl phosphorane (41) and 2-aryl benzoic acid (40) was sonicated at room temperature in dry DCM as a solvent. Using an irradiating power of $200 \mathrm{~W}$ for 10 mins was the most efficient resulting in product yield of $97 \%{ }^{54}$.

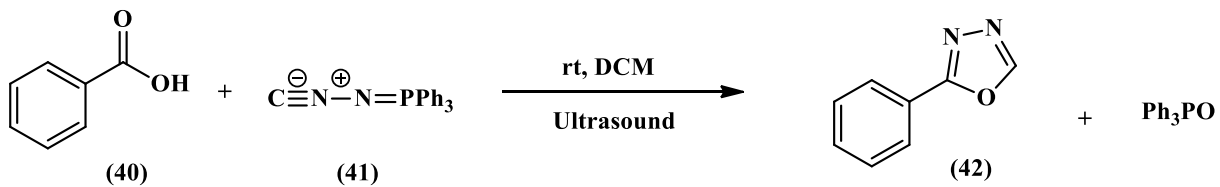

Scheme 32. Ultrasound synthesis of 1,3,4-oxadiazole 
Similarly, Rouhani and coworkers synthesized 1,3,4-oxadiazole using ultrasound irradiation as the source of energy. The reaction involved the condensation of acenaphthoquinone (44), $(N-$

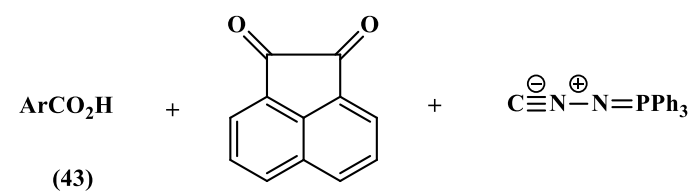

(44) isocyanimino) triphenylphosphorane and aromatic carboxylic acid (43) in acetonitrile at room temperature to give the 1,3,4-oxadiazole (45) ${ }^{55}$.

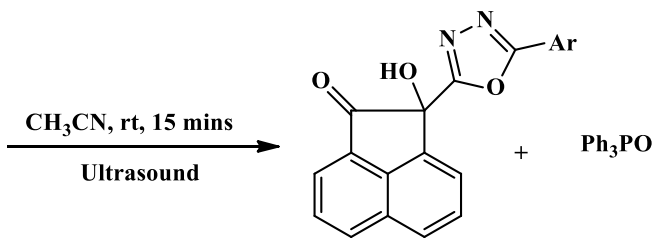

(45)

Scheme 33. Ultrasound synthesis of 1,3,4-oxadiazole using acenapthoquinone as starting material

\subsubsection{Visible light-induced coupling of hydrazides and ketones}

One-pot cyclization to from 1,3,4-oxadiazole from hydrazides and ketones following hydrazone intermediate route has been induced by visible light Yadav, and Yadav first reported the synthesis of 2,5-disubstituted-1,3,4-oxadiazoles from the one-pot coupling between hydrazides and ketones in the presence of visible light (green light-emitting diodes, $\lambda=535 \mathrm{~nm}$ ) The use of eosin Y organophotoredox catalyst is quintessential, alongside organic bases such as $\operatorname{Pr}_{2} \mathrm{NEt}$ and oxygen source such as air or oxygen balloon as little or no product was formed in the absence of any of the reagents or catalyst ${ }^{56}$.

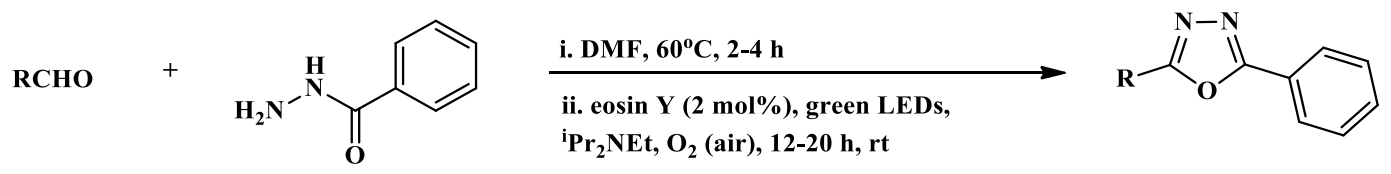

Scheme 34. Visible light-induced synthesis of 1,3,4-oxadiazoles

The reaction occurred faster with better yield when electron-donating groups were attached to the aromatic ring on the hydrazide or ketones. The overall reaction gave good to excellent yields (70-90)\% regardless of the substituent attached.

Also, visible light had been reported to induce the decarboxylation-cyclization between hydrazides and diketones using photocatalyst such as eosin $\mathrm{Y}$ (provides optimal condition as regarded to other photocatalysts).
The reaction was optimized when $\mathrm{K}_{2} \mathrm{CO}_{3}$ was used as base in DMSO. This synthetic route was predicted to follow a radical reaction pathway as no reaction occurred when radical scavenging TEMPO $(2,2,6,6-$ tetramethyl-1-piperindinyloxyl) was added to the reaction mixture. Also, $\mathrm{O}_{2}$ is necessary for the reaction to occur since no product was gotten in $\mathrm{N}_{2}$ atmosphere. Under the optimized condition, no reaction progress occurred in the absence of visible light ${ }^{57}$.

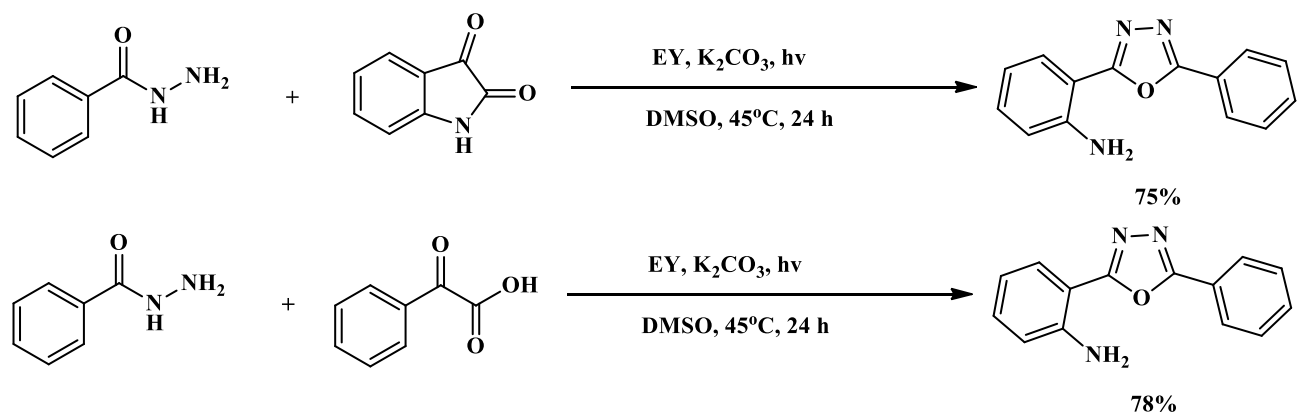

Scheme 35. Visible light-induced coupling between hydrazides and diketones

One-pot coupling between $\alpha$-keto acids and acylhydrazides to yield the desired 1,3,4-oxadiazole route gave fair to a good yield of the product in visible light as shown in Scheme 36, using PANI (polyaniline)g- $\mathrm{C}_{3} \mathrm{~N}_{4}-\mathrm{TiO}_{2}$ composite as catalyst ${ }^{58}$. 


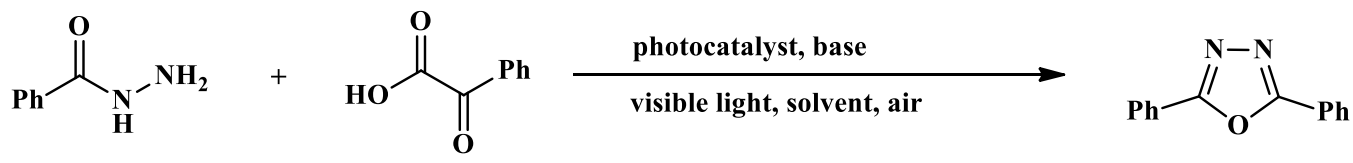

Optimum reaction conditions: Photocatalyst $=$ PANI $(40 \%)-g-\mathrm{C}_{3} \mathrm{~N}_{4}-\mathrm{TiO}_{2}(60 \mathrm{mg})$, base $=\mathrm{K}_{2} \mathrm{CO}_{3}$ solvent $=$ DMF, irradtion with a $14 \mathrm{~W}$ CFL under air at room temperature

Scheme 36. Visible light-induced synthesis of oxadiazoles using PANI composite as a catalyst

\subsubsection{Cyclodehydration through diacylhydrazine intermediate}

Stabile and coworkers carried out the cyclodehydration to 1,3,4-oxadiazole using $p$-toluene sulfonyl chloride for dehydration. The reaction follows a diacylhydrazine intermediate (46). The reaction was started from carboxylic acids and hydrazides first using TBTU and acetonitrile at room temperature. Optimum conditions included the use of diisopropylethylamine (DIPEA) as base and TBTU as coupling agent ${ }^{59}$.

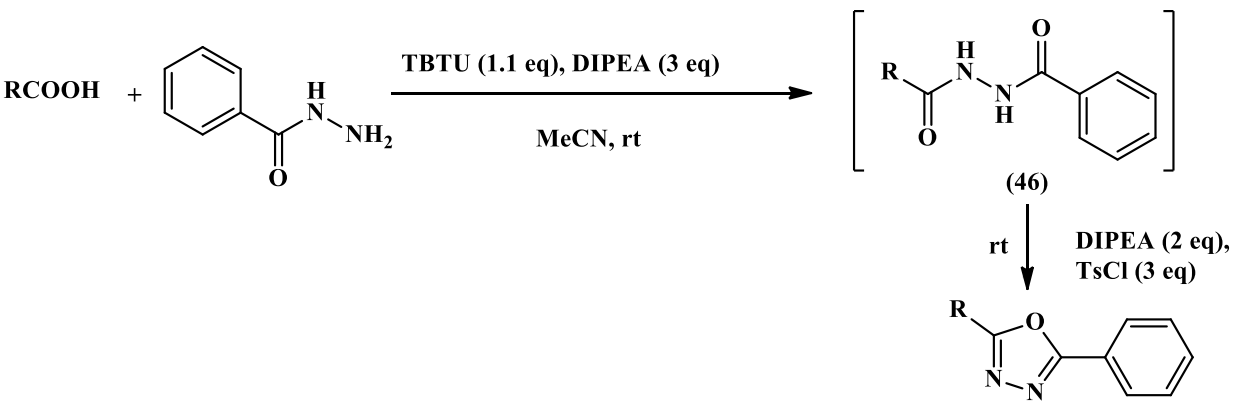

Scheme 37. Cyclodehydration of diacylhydrazine using DIPEA

Good to excellent yields ranging from (76-90)\% under the optimal conditions were obtained.

Mihailović and coworkers carried cyclodehydration of diacylhydrazine intermediate, derived from phenolic acids. Treatment of the diacylhydrazine with thionyl chloride in DMF resulted in the cyclization, yielding the 1,3,4-oxadiazole ${ }^{60}$.

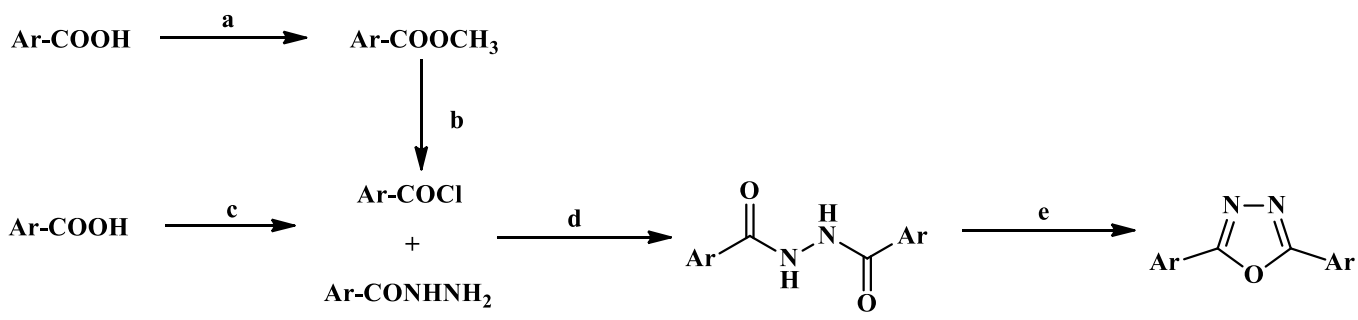

Reagents and conditions: (a) $\mathrm{H}_{2} \mathrm{SO}_{4}, \mathrm{MeOH}, 5 \mathrm{~h}$, reflux; (b) $\mathrm{N}_{2} \mathrm{H}_{4} \cdot \mathrm{H}_{2} \mathrm{O}$, EtOH, $12 \mathrm{~h}$, reflux;

(c) $\mathrm{SOCl}_{2}, \mathrm{DMF}$, DCM, $2 \mathrm{~h}$, rt; (d) THF, $6 \mathrm{~h}$, rt; (e) $\mathrm{SOCl}_{2}, 6 \mathrm{~h}$, reflux

Scheme 38. Cyclodehydration of diacylhydrazine using $\mathrm{SOCl}_{2}$

\subsubsection{Cyclization of ethyl carbazate with $\mathrm{N}$ - acylbenzotriazoles}

Wet-osot and colleagues synthesized 1,3,4-oxadiazoles with diacylhydrazine as intermediate. $N$-acylation/ dehydrative cyclization of ethyl carbazate (47) and $N$-acylbenzotriazole yielded the desired product in a one pot, short reaction time synthesis using ultrasonic irradiation. The $N$-acylation step was carried out using $\mathrm{K}_{2} \mathrm{CO}_{3}$ and DMAP (10 mol \%) as base and catalyst respectively in DCM, treatment of the formed diacylhydrazine with $\mathrm{Ph}_{3} \mathrm{P}-\mathrm{I}_{2}$ and $\mathrm{Et}_{3} \mathrm{~N}$ yielded to 1,3,4-oxadiazole in moderate to excellent yields (63\%-90\%), bearing an ethoxy group at position $2^{61}$. 


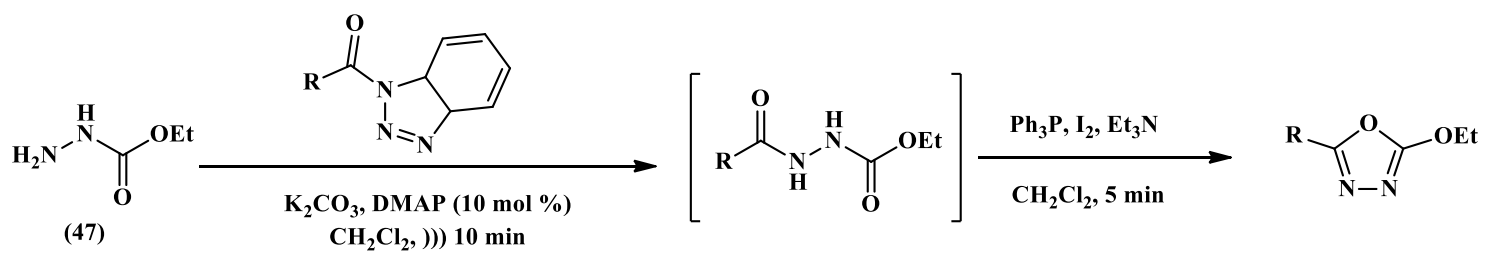

Scheme 39. Synthesis of 1,3,4-oxadiazole using triazoles as starting material

2.3.18. 1,3-Dipolar cycloaddition of nitrile imine with carbon dioxide

1,3-Dipolar cycloaddition of $\mathrm{CO}_{2}$ as dipolarophile with hydrazonyl chlorides as nitrile imine (48) gave 1,3,4-oxadiazole- $(3 H)$-ones in good yields. The reaction was mediated with $\mathrm{CsF} / 18$-crown- 6 to enhance the reactivity of carbon dioxide. Optimal conditions included the use of toluene as solvent and 2.5/1.2 equivalent of $\mathrm{CsF} / 18$-crown-6 ether.<smiles>[R]NN=C([R])Cl</smiles>

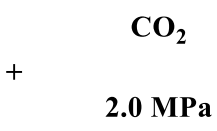

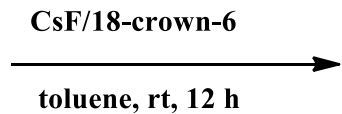<smiles>[R]c1nn([R2])c(=O)o1</smiles>

(48)

Scheme 40. Cycloaddition of nitrile imine with carbon dioxide to yield oxadiazoles

The reaction gave good yields ranging from $61 \%$ to 95\% for the various aromatic substituted $R_{1}$ and $R_{2}$ groups, and also the high yield of $86 \%$ with butyl substituted $\mathrm{R}_{2}$ group ${ }^{62}$.

\subsubsection{Di-tert butyl peroxide assisted condensation of aryl tetrazoles with aldehydes}<smiles>[R]1ccc(-c2nn[nH]n2)cc1</smiles><smiles>[R2]c1ccc(C=O)cc1</smiles>

This route involved a one-pot radical-promoted crossdehydrogenative condensation between aryl tetrazoles (49) and aldehydes, starting from the $N$-acylation of the tetrazole, followed by thermal rearrangement that led to the expulsion of $\mathrm{N}_{2}$. This advantageous base and metalfree synthesis gave yields as high as $87 \%{ }^{63}$.

Scheme 41. DTBP assisted condensation of aryl tetrazoles with aldehydes to give oxadiazoles

\subsubsection{Microwave-assisted synthesis of $1,3,4$ -} oxadiazoles

Microwave irradiation had been adapted for the synthesis of 1,3,4-oxadiazole in reduced reaction time and high yields. Desai and coworkers carried out the microwave-assisted synthesis of 1,3,4-oxadiazole using the aforementioned oxidative cyclization with acetic anhydride in the microwave for 7 minutes ${ }^{64}$. 


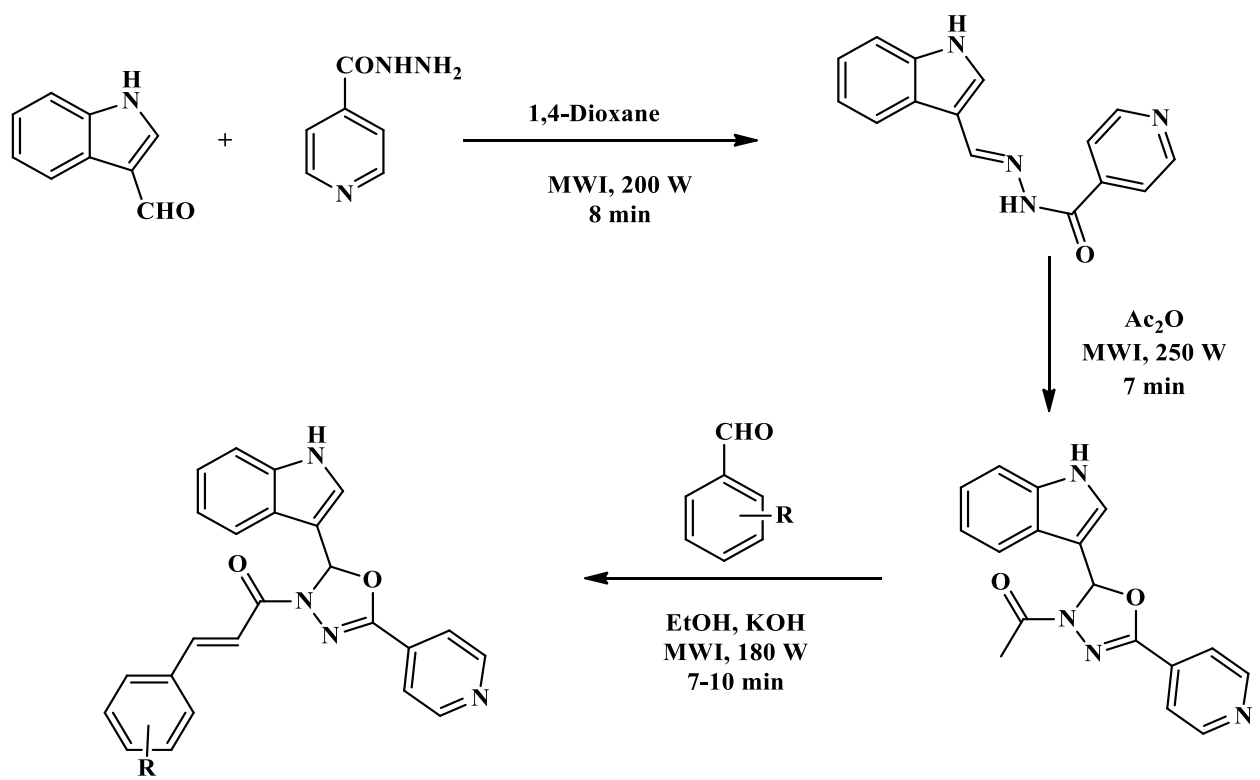

Scheme 42. Microwave-assisted synthesis of 1,3,4-oxadiazoles

\subsubsection{Electrosynthesis of Hydrazones}

Singh and co-workers developed an electro-synthetic method for 1,3,4-oxadiazole from the corresponding hydrazones. Cyclization was facile, being concluded in less than $4 \mathrm{hrs}$ at room temperature. After optimization, it was revealed that carrying out the reaction in methanol using $\mathrm{NaClO}_{4}$ as supporting electrolyte gave the highest yields. Good to excellent yields ranging from $57 \%$ to $94 \%$ were obtained ${ }^{65}$.<smiles>[R]C=NNC([R])=O</smiles>

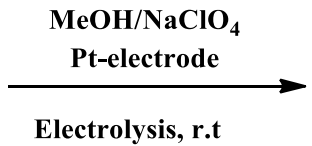<smiles>[R]c1nnc([R])o1</smiles>

Scheme 43: Facile electrosynthesis to 1,3,4-oxadiazoles

\section{Biological activities}

\subsection{Anticancer/antitumor activity}

1,3,4-oxadiazole derivatives have shown very promising anticancer efficacy. Series of oxadiazole derivatives were synthesized by Caneschi and coworkers and compound (50) revealing highest activity against mammary carcinoma (4T1) and colon cancer (CT26) cell lines with $\mathrm{IC}_{50}$ of 1.6 and $6.3 \mu \mathrm{M}$ respectively and SI of $14.5^{11}$. Lakshmithendral and coworkers synthesized a library of 2-(phenoxy methyl)5-phenyl-1,3,4-oxadiazole derivatives using molecular docking for designing molecules having estrogen receptor with potent activity against breast cancer cell lines MCF-7 and MDA-MB-453 with compounds (51a, $\mathrm{IC}_{50}: 11.12 \mu \mathrm{M}$ (MCF-7), $12.95 \mu \mathrm{M}$ (MDA-MB-453) and (51b, IC $50: 10.25 \mu \mathrm{M}$ (MCF-7), $10.51 \mu \mathrm{M}$ (MDAMB-453) showing the highest activity in the series and compound (51b) further exhibiting reduced cell viability ${ }^{34}$. Bajaj and coworkers also synthesized 1,3,4oxadiazoole-2-thiones that showed significant inhibitory activity against MCF-7 cell lines with compound (52) being the most potent in the series. SAR showed that having a less bulky amine group at the $\mathrm{R}_{1}$ position led to enhanced inhibition. The molecular docking studies pointed out that amine has the good binding capacity to the thymidine phosphorylase active site. This binding was enhanced through hydrogen bonding to some amino acid residues, thereby unveiling compound (52) with $\mathrm{GI}_{50}$ of 0.041 as a potent anticancer agent against MCF-7 cell lines ${ }^{66}$. Chaves and coworkers synthesized gold (I) complexes containing 1,3,4-oxadiazole and compound (53) showed auspicious activity against murine melanoma B16F10 $\left(\mathrm{IC}_{50}<0.10 \mu \mathrm{M}\right)$, colon cancer CT26.WT $\left(\mathrm{IC}_{50}=0.23\right.$ $\mu \mathrm{M})$ cell lines and non-tumor kidney cell line BHK-21 $\left(\mathrm{IC}_{50}=0.23 \mu \mathrm{M}\right)^{67}$. Other compounds showing auspicious anticancer activity included compound (54) having $\mathrm{IC}_{50}$ of $1.7 \mu \mathrm{M}$ and $0.05 \mu \mathrm{M}$ against MCF7 (breast cancer) and HeLa (cervix adenocarcinoma) respectively ${ }^{68}$, compound (55) having $\mathrm{IC}_{50}$ values of $0.22 \mu \mathrm{M}$ and $1.3 \mu \mathrm{M}$ against androgen-dependent (LNCaP) and androgen-independent (PC-3) prostate cancer cell lines ${ }^{69}$, compound (56) inhibiting the growth of T-47D breast cancer cell line by $90.47 \%$ at 
$10 \mu \mathrm{M}$ and also showing inhibition of over $80 \%$ against other breast cancer cell lines such as SK-MEL-5 melanoma and MDA-MB-468 ${ }^{70}$ and compound (57) showing significant growth inhibition on all human cancel cell with $\mathrm{GI}_{50}$ ranging from 1.30 to $5.64 \mu \mathrm{M}^{71}$.

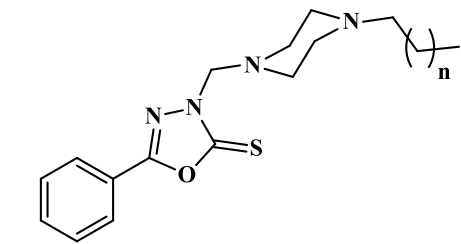

(50)

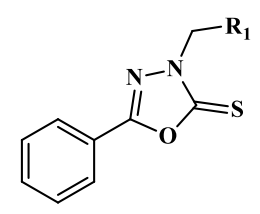

(51)

$R_{1}=$ 4-hyroxyaniline<smiles>[R]c1ccc(-c2nnc(CCc3ccc(C#N)cc3OC)o2)cc1</smiles>

a: $\mathbf{R}_{1}=\mathrm{OCH}_{3}$

b: $\mathbf{R}_{1}=\mathbf{F}$

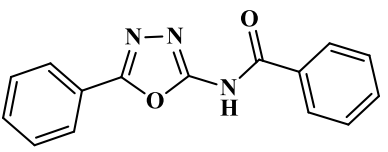

(55)

(53)

(54)

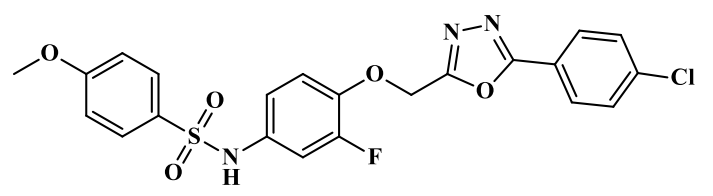

(56)

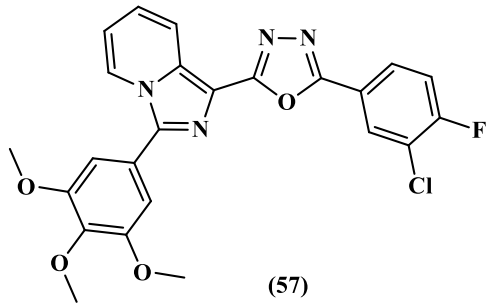

Figure 4. Some 1,3,4-oxadiazole derivatives with anticancer activity

\subsection{Antifungal activity}

Fungal growth had been noted as one of the chief diseases affecting food production. 1,3,4-Oxadiazole derivatives have been synthesized with potential activity to combat this prevalent issue. $\mathrm{Yu}$ and colleagues synthesized various 1,3,4-oxadiazole derivatives showing fungicidal activity against rice sheath blight (RSB) and sorghum anthracnose (SA), with compounds (58a, $\left.\mathrm{EC}_{50}: 0.85 \mathrm{mg} / \mathrm{L}\right)$ and $\mathbf{( 5 8 b}$, $\left.\mathrm{EC}_{50}: 0.88 \mathrm{mg} / \mathrm{L}\right)$ being the most potent against rice sheath blight (RSB), having higher activity than commercially available Tebuconazole ${ }^{42}$. Compound (58c, $\mathrm{EC}_{50}$ : $\left.1.03 \mathrm{mg} / \mathrm{L}\right)$ being most active against sorghum anthracnose showing better activity when compared to pyraclostrobin. Synthesis and evaluation of the antifungal activity of 1,3,4-oxadiazole fused pyridine derivatives revealed potency against Sclerotium rolfsii and Macrophomina phaseolina with compounds (59a) and (59b) showing significant activity against Sclerotium rolfsii having Z.O.I of $0.3 \mathrm{~cm}$ and compound (59c) showing the best activity against Macrophomina phaseolina with Z.O.I of $0.3 \mathrm{~cm}$ 72. Karaburun and coworkers synthesized novel benzimidazole-1,3,4-oxadiazole derivatives which showed promising activity against $C$. ablicans with compounds $(60 a \&$ b) showing better activity than Ketoconazole $^{73}$. The activity of compounds $(60 \mathbf{a} \boldsymbol{\&} \mathbf{b})$ was proposed to stem out of the inhibition of ergosterol biosynthesis in the fungal membrane as seen with most widely used antifungal drugs. In addition, compound (61) a novel quinazolin-4(3H)-one derivative containing 1,3,4-oxadiazole scaffold, exhibited excellent antifungal activity against plant pathogenic fungi Rhizoctonia solani and Fusarium graminearum having $\mathrm{EC}_{50}$ values of $11.01 \mu \mathrm{g} / \mathrm{mL}$ and $36.00 \mu \mathrm{g} / \mathrm{mL}$ respectively, an activity much higher than that of the agriculturally used hymexazol fungicide ${ }^{74}$. 


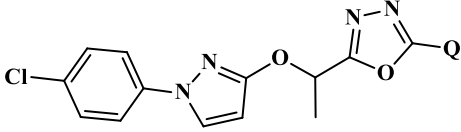

(58)

a: $\mathbf{Q}=3$-pyridinyl b: $Q=4$-(Trifluoromethyl)phenyl c: $\mathbf{Q}=4$-Chlorophenyl

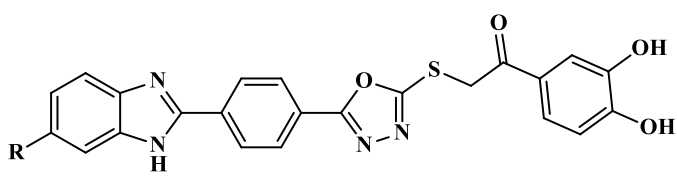

(60)

$$
\text { a: } \mathbf{R}=\mathbf{F}
$$$$
\text { b: } \mathbf{R}=\mathbf{C l}
$$

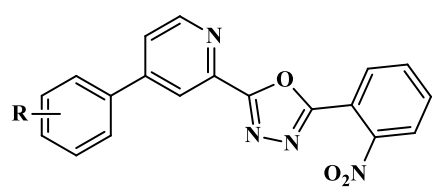

(59)

a: $\mathbf{R}=2$-Trifluoromethyl

b: $\mathbf{R}=\mathbf{3 , 4}$-Difluoro

c: $\mathbf{R}=4$-Cyanophenyl

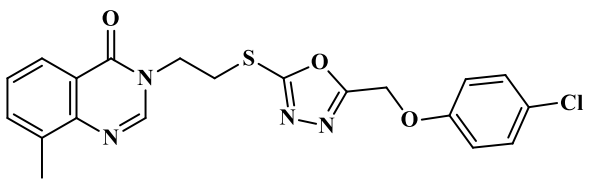

(61)

Figure 5. Some 1,3,4-oxadiazole derivatives with antifungal activity

\subsection{Antibacterial activity}

Xanthomonas oryzae pv. Oryzae (Xoo), a Gramnegative bacterium affecting rice production in countries like Japan, Song and workers synthesized series of 1,3,4-oxadiazole moieties which have potent activities against Xoo with compound (62) being the most promising with $\mathrm{EC}_{50}$ value of $4.78 \mu \mathrm{M}$, over 18 times more potent than the commercially used bismerthiazol ${ }^{12}$. The proteomics of (62) revealed that 349 proteins out of the 1363 in Xoo were differentially expressed and may be involved in purine metabolism. Staphylococcus aureus infection has become a prominent health challenge with the rise of methicillinresistant $S$. aureus (MRSA) worsening the present situation ${ }^{75}$, being identified by the World Health Organization in 2017 as one of the twelve deadliest drug-resistant bacteria ${ }^{76}$. Development of new antibacterial agent is ongoing with Guo and colleagues synthesizing novel norfloxacin-1,3,4-oxadiazole hybrids, having excellent efficacy both against S. aureus (MIC: $2 \mu \mathrm{g} / \mathrm{mL}$ ) and methicillin-resistant Staphylococcus aureus (MRSA1-3) (MIC: 0.25-2 $\mu \mathrm{g} / \mathrm{mL}$ ) bacteria with compound (63) being the most active in the library, even more, potent than commonly used vancomycin, destroying the membranes of both $S$. aureus and MRSA2 in short time ${ }^{77}$. Compound (63) showed an added advantage of low cytotoxicity $\left(\mathrm{IC}_{50}\right.$ of $>200 \mu \mathrm{g} / \mathrm{mL}$ ). Farshori and coworkers synthesized new 1,3,4-oxadiazole series bearing fatty acid side chains which showed promising antibacterial activity against both gram-positive and gram-negative bacteria with compound (64) showing one of the most promising activity; having $\mathrm{ZO} 1$ of $27.5 \mathrm{~mm}$ against $P$. aeruginosa, $22.4 \mathrm{~mm}$ against $K$. pneumoniae and $S$. pyogenes, with $23.4 \mathrm{~mm}$ against E. $_{\text {coli }}{ }^{78}$.<smiles>[R2]CSc1nnc([R])o1</smiles>

(62)

$\mathrm{R}_{1}=4-\mathrm{Cl}-\mathrm{C}_{6} \mathrm{H}_{4}$, $\mathrm{R}_{2}=\mathbf{3 , 4 - \text { di-OCH}}$-pyridin-2yl<smiles>[R]c1nnc(CN2CCN(c3cc4c(cc3F)c(=O)c(C(=O)O)cn4CC)CC2)o1</smiles>

$\mathbf{R}=$ 3-methoxyphenyl

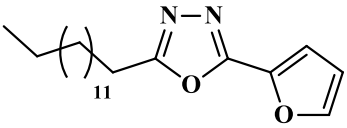

(64)

Figure 6. Some 1,3,4-oxadiazole derivatives with antibacterial activity

\subsection{Antitubercular activity}

WHO has noted tuberculosis as one of the deadliest infectious diseases, being ranked number two on the death-causing diseases ${ }^{13}$. Fighting tuberculosis does not get easier as multidrug-resistant tuberculosis (MDR TB), and extensively drug-resistant tuberculosis (XDR $\mathrm{TB})$ is emerging. Therefore, extensive research is needed to tackle this challenge ${ }^{79-81}$. In that vein, a series of 1,3,4-oxadiazole derivatives bearing indole and pyridine have been synthesized and tested for their antitubercular activity against Mycobacterium tuberculosis $\mathrm{H}_{37} \mathrm{Ra}$ (MTB) and Mycobacterium bovis BCG in both their dormant and active sites. The synthesized library showed good antitubercular activity against Mycobacterium bovis with low cytotoxicity using HeLa, A549 and PANC-1 cell lines. Compound 
(65a MIC: active state $=0.94 \mu \mathrm{g} / \mathrm{mL}$, dormant state $=$ $1.19 \mu \mathrm{g} / \mathrm{mL})$ and $(\mathbf{6 5} \mathrm{b} \mathrm{MIC}:$ active state $=1.03 \mu \mathrm{g} / \mathrm{mL}$, dormant state $=0.85 \mu \mathrm{g} / \mathrm{mL}$ ) being the most potent of the lot, having SI values greater than $22 \mu \mathrm{g} / \mathrm{mL}$ for both the active and dormant state ${ }^{64}$. Similarly, Dhumal and coworkers synthesized novel 1,3,4-oxadiazoles with pyridyl and thiazolyl scaffolds, showing antitubercular activity against $M$. bovis BCG, with compound (66a, MIC: active state $=2.65 \mu \mathrm{g} / \mathrm{mL}$, dormant state $=3.95$ $\mu \mathrm{g} / \mathrm{mL})$ and $(\mathbf{6 6 b}, \mathrm{MIC}=2.56 \mu \mathrm{g} / \mathrm{mL}$, dormant state $=$ $5.89 \mu \mathrm{g} / \mathrm{mL}$ ) being the most promising in the series, with low cytotoxicity $\left(\mathrm{CC}_{50} \text { : }>100 \mu \mathrm{g} / \mathrm{mL}\right)^{82}$. Very recently, Ambhore and coworkers synthesized series of compounds containing 1,3,4-oxadiazole scaffold having promising anti-tubercular activity with MIC value ranging from 3.9-7.81 $\mu \mathrm{g} / \mathrm{mL}$ with compounds (67 a-d) showing the highest activity against multidrug resistance $M t b$ (MTCC 300) all having MIC values of $3.9 \mu \mathrm{g} / \mathrm{mL})^{83}$. Karabanovich and coworkers develop moieties containing 1,3,4-oxadiazole (68) having auspicious activity against Mycobacterium tuberculosis, including multidrug and extensively drugresistant strains, with many of the compounds out of the library having MIC value of $0.03 \mu \mathrm{g} / \mathrm{mL}^{84}$.

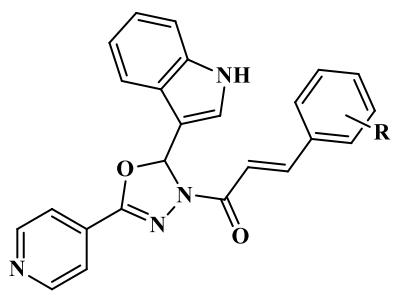

(65)

a: $\mathbf{R}=\mathbf{2 - O H}$ b: $\mathbf{R}=\mathbf{2}-\mathrm{NO}_{\mathbf{2}}$

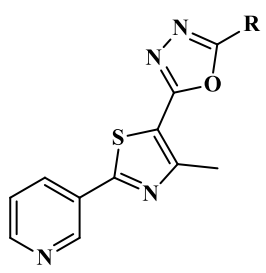

(66)

a: $\mathbf{R}=2$-methoxyphenyl b: $\mathbf{R}=2$-nitrophenyl

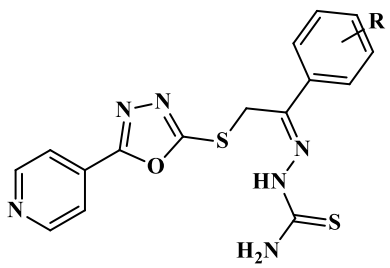

(67)

a: $\mathbf{R}=4$-bromo

b: $\mathbf{R}=3$-nitro

c: $R=3,4-$ dichloro

$\mathbf{d}: \mathbf{R}=\mathbf{H}$<smiles>[R]Sc1nnc(-c2cc([N+](=O)[O-])cc([N+](=O)[O-])c2)o1</smiles>

(68)

Figure 7. Some 1,3,4-oxadiazole derivatives with antitubercular activity

\subsection{Anti-inflammatory activity}

Anti-inflammatory activity of 1,3,4-oxadiazoles fragments coupled to betulonic acid core was evaluated by Popov and coworkers ${ }^{14}$. Inflammation was induced by concanavalin $\mathrm{A}$ and histamine in mouse paw edema models. Introduction of 1,3,4-oxadiazole fragments led to an increase anti-inflammatory activity as compared to the activity of the starting betulonic acid, with compound (69), being the most potent in the library containing 1,3,4-oxadiazole, reducing the inflammation by $86 \%$ and $82 \%$ as compared to the started indomethacin on the histamine-induced inflammation and concanavalin A-induced inflammation respectively. A library of 1,3,4-oxadiazole/oxime hybrids were synthesized, showing promising COX inhibition for both COX-1 and COX-2 enzymes. The compounds excellently reduced the carrageenaninduced inflammation in rat's paws, without leading to a reduction in the reactive oxygen species (ROS) level in tissues. Compounds (70) and (71) showed leading activity of the series, having an inhibition of $100 \%$ and
$109 \%$ of indomethacin activity respectively after 4 hours with zero ulcer index and $\mathrm{IC}_{50}$ of compound (70) being $1.10 \mu \mathrm{M}$ for COX-1 and $2.30 \mu \mathrm{M}$ for COX2 and $\mathrm{IC}_{50}$ of compound (71) being $0.94 \mu \mathrm{M}$ for COX1 and $5.00 \mu \mathrm{M}$ for COX-2 ${ }^{85}$. Before this work, AbdEllah and coworkers had synthesized new series of the oxadiazole/oxime hybrids, and they also showed potent anti-inflammatory activity, with compound (72) being the most dominant in the series, with the antiinflammatory activity of $116 \%$ relative to indomethacin after 4 hours ${ }^{86}$. Compound (72) also had $\mathrm{IC}_{50}$ values of $2.12 \mu \mathrm{M}$ and $0.75 \mu \mathrm{M}$ for COX-1 and COX-2, respectively. 5,6-diphenyl-1,2,4-triazine-3(2H)-one derivatives were having 5-substituted 1,3,4-oxadiazoles were synthesized and evaluated for their antiinflammatory activity using the in vitro albumin denaturation assay technique. Positive results were obtained as compound (73) showed inhibition of $80.81 \%$ and potency of $94.30 \%$ for carrageenaninduced paw oedema with indomethacin in $0.3 \%$ sodium CMC solution as standard ${ }^{87}$. 


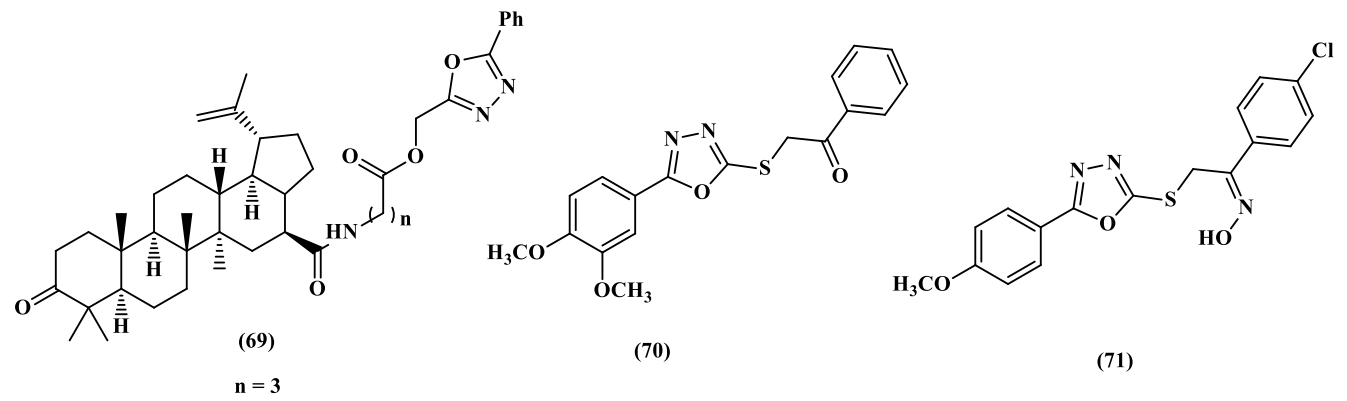

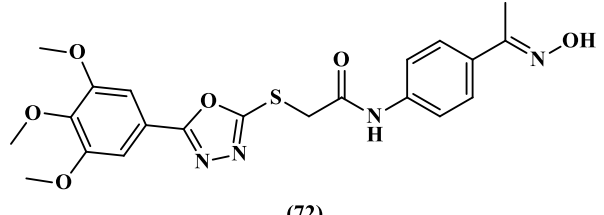

(72)

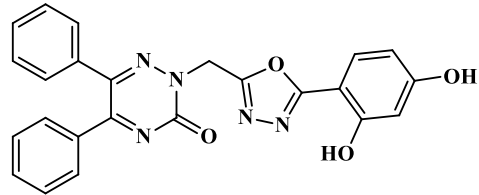

(73)

Figure 8. Some 1,3,4-oxadiazole derivatives with anti-inflammatory activity

\subsection{Analgesic activity}

1,3,4-oxadiazoles, alongside being potent antiinflammatory agents, have also proven to be possible analgesic agents with compound (74) standing out in a series of synthesized 1,3,4-oxadiazole/oxime hybrid. The analgesic activity was evaluated using the tail-flick method and compound (74) showed significant analgesic activity with a $196.30 \%$ rise in tail-flick latency time as compared to the $123.90 \%$ of paracetamol ${ }^{86}$. Using the acetic acid-induced writhing method, compound (75) showed better analgesic activity with $67.43 \%$ reduction in writhing as compared to the $58.16 \%$ reduction brought about by aspirin ${ }^{88}$. In like manner, compound (76) recorded a $74.84 \%$ reduction in writhing, being the most potent in the series of triazine-3 $(2 H)$-one derivatives bearing 1,3,4oxadiazole ${ }^{87}$.<smiles>C/C(=N\O)c1ccc(NC(=O)CSc2nnc(-c3ccc(Cl)cc3)o2)cc1</smiles>

(74)

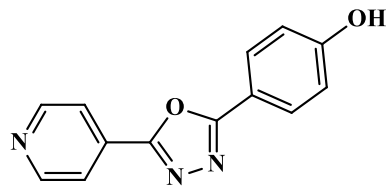

(75)<smiles>O=c1nc(-c2ccccc2)c(-c2ccccc2)nn1Cc1nnc(-c2ccc([N+](=O)[O-])cc2)o1</smiles>

(76)

Figure 9. Some 1,3,4-oxadiazole derivatives with analgesic activity

\subsection{Antimalarial activity}

Malaria is a prevalent public health challenge mainly affecting countries in the tropical zone of the world with about 95 countries been impacted, covering regions in Africa, Eastern Mediterranean region and South-East Asia (WHO, 2016). It has led to the loss of many lives and still affects millions of people. Therefore, the need for the emergence of new antimalarial to tackle this challenge, alongside the problem of drug resistance by the protozoan parasite is eminent. Thakkar and coworkers synthesized 1,3,4-oxadiazole analogues having antimalarial activity against $P$. falciparum, with in silico docking showing that the molecules inhibit the enzyme $P$. falciparum dihydrofolate reductase with compound (77: $\left.\mathrm{IC}_{50}=0.301 \mu \mathrm{M}\right)$ being the most potent 1,3,4-oxadiazole in the series, even more, potent than 
Pyrimethamine used as reference ${ }^{89}$. Similarly, compound (78) showed the highest activity against 3D7 strains of $P$. falciparum with $\mathrm{IC}_{50}$ of $0.258 \mu \mathrm{M}$ and $\mathrm{IC}_{50}$ of $0.863 \mu \mathrm{M}$ against chloroquine-resistant RKL 9 strain of the parasite in the series of new pyrazole-1,3,4- oxadiazole hybrids ${ }^{90}$. Ladani and Patel synthesized 1,3,4-oxadiazole analogues with quinoline scaffold, carrying out antimalarial evaluation and compound (79) better activity than the quinine reference, with $\mathrm{IC}_{50}$ of $0.089 \mu \mathrm{M}^{91}$.

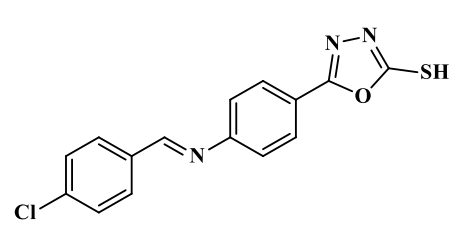

(77)

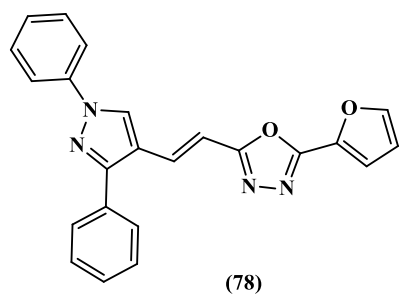

(78)

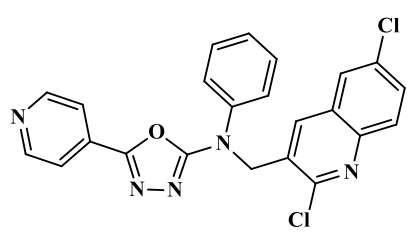

(79)

Figure 10. Some 1,3,4-oxadiazole derivatives with antimalarial activity

\subsection{Anti-diabetic Activity}

Diabetes, a group of metabolic disorders characterized by high levels of blood sugar, weakened insulin production or liver insulin resistance is one of the health challenges plaguing millions of lives ${ }^{92}$. Type-II diabetes mellitus is the most prevalent of all diabetes, with a global increase from 108 million affected people to 422 million people between 1980 to $2014^{93,94}$. The use and development of oral anti-hyperglycemic agents are generally used to combat this global challenge. 1,3,4-oxadiazoles are gaining attention as a possible anti-hyperglycemic agent as recently, new hybrids of benzothiazole-1,3,4-oxadiazole-4-thiazolidinone were synthesized and screened for in vivo anti-hyperglycemic potency on streptozotocin-induced diabetic rat models, and all the compounds reduced the blood sugar levels with compound (80) being the best overall, reducing the glucose concentration to $157.15 \mathrm{mg} / \mathrm{dL}$, is better than the reference drug, pioglitazone which reduced the glucose level to $178.32 \mathrm{mg} / \mathrm{dL}$. It also had superior inhibition of $\alpha$-glucosidase $(\alpha$-glucosidase inhibitors are widely used in the treatment of patients with type II diabetes) to the acarbose standard with an $\mathrm{IC}_{50}$ value of $0.21 \mu \mathrm{M}$ as compared to the $18.5 \mu \mathrm{M}$ of the standard ${ }^{95}$. In the continuous attempt to mitigate the diabetes challenge, Shyma and colleagues synthesized 1,3,4oxadiazole containing 6-methyl pyridine moiety with compounds (81) and (82) showing good inhibition of $\alpha$-amylase and $\alpha$-glucosidase ${ }^{96}$. Compound (81) had inhibition of $70.38 \%$ for $\alpha$-amylase and $59.12 \%$ for $\alpha$-glucosidase, while compound (82) had inhibition of $69.73 \%$ for $\alpha$-amylase and $62.48 \%$ for $\alpha$-glucosidase. Compound (83) showed the highest activity in the series of synthesized 2-((benzothiazole-2-ylthio)methyl)-5phenyl-1,3,4-oxadiazole derivatives by reducing the blood sugar in alloxan-induced diabetes in rats by $66.84 \%$ with the compounds recording good $\mathrm{LD}_{50}$ values of (300-2000) $\mathrm{mg} / \mathrm{kg}^{97}$.

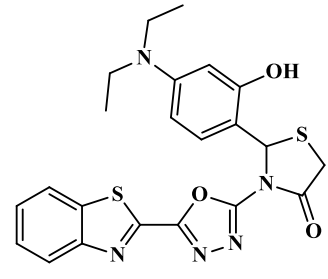

(80)<smiles>Cc1ccc(-c2nnc(-c3cccc(Cl)c3Cl)o2)cc1</smiles>

(81)<smiles>C=C1OC(c2ccc(C)cc2)=NC1CN1CCCCC1</smiles>

(82)<smiles>Cc1ccc2nc(SCc3nnc(-c4ccc(N)cc4)o3)sc2c1</smiles>

(83)

Figure 11. Some 1,3,4-oxadiazole derivatives with anti-diabetic activity

\subsection{Anti-HIV/antiviral activity}

Abdel-Rahman and colleagues synthesized new 1,3,4oxadiazole derivatives alongside their acyclic nucleoside analogues, evaluating for their anti-HIV 
efficacy as reverse transcriptase inhibitors, with a good number of compounds in the series showing moderate to high inhibition activity ${ }^{98}$. Compound (84) displayed the highest potency with $\mathrm{IC}_{50}$ of $1.44 \mu \mathrm{M}$ and therapeutic index of $3.15 \times 10^{7}$. 1,3,4-Oxadiazoles have also shown power against plant viruses such as the tobacco mosaic virus (TMV) as $\mathrm{Wu}$ and coworkers synthesized novel 1,3,4-oxadiazole derivatives, testing for their antiviral activity against tobacco mosaic virus using the half-leaf method with compound (85) having an $\mathrm{EC}_{50}$ value of $301.83 \mu \mathrm{g} / \mathrm{mL}$ which was even better than that of Ningnanmycin used as standard ${ }^{99}$. Two years later, Gan and coworkers also synthesized 1,3,4-

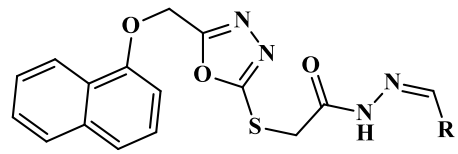

(84)

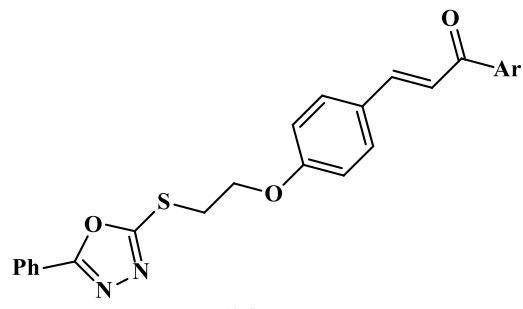

(86)

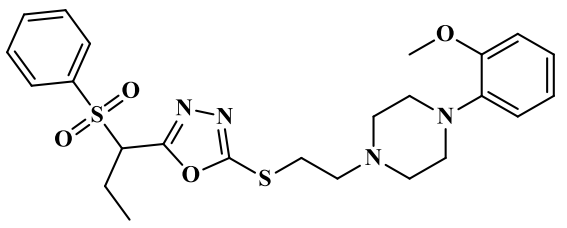

(87)

oxadiazole moieties, evaluating them for their tobacco mosaic viral activity and oxadiazole (86) showed the highest activity amongst the oxadiazoles, having an $\mathrm{IC}_{50}$ value of $33.66 \mu \mathrm{M}$, which was comparable to that of the commercial Ningnanmycin $(36.85 \mu \mathrm{g} / \mathrm{mL})$ and much better than that of Ribavirin $(88.52 \mu \mathrm{g} / \mathrm{mL})^{15}$. Tan and colleagues synthesized 1,3,4-oxadiazole derivatives which can inhibit viral antigens, $\mathrm{HBsAg}$ and $\mathrm{HBeAg}$ in a concentration-dependent manner having no cytotoxic effect, hence can serve as a potential treatment for hepatitis B (HBV) virus infection. Compound (87) had the highest activity having $\mathrm{EC}_{50}$ value of $1.63 \mu \mathrm{M}$, being better than the Lamivudine standard ${ }^{100}$.<smiles>COC(=O)CSc1nnc(-c2cnc(C)nc2N)o1</smiles>

(85)

$\mathrm{Ar}=2,4-\mathrm{diCl}-\mathrm{C}_{6} \mathrm{H}_{3}$

Figure 12. Some 1,3,4-oxadiazole derivatives with antiviral activity

\subsection{Insecticidal activity}

Studies have shown that compounds containing 1,3,4oxadiazole can serve as potent insecticides. Ding and coworkers synthesized new fraxinellone-based thioethers with 1,3,4-oxadiazole moieties with all the analogues showing insecticidal activity against oriental armyworm, Mythimna separata; a lot of the synthesized compounds had higher final mortality rates (FMR) than the Toosendanin standard used, with compound (88) having the highest final mortality rate of $75.9 \%$ after 34 days being $24 \%$ more potent than the commercial available Toosendanin insecticide ${ }^{101}$. Similarly, Guo and coworkers synthesized sarisan derivatives containing 1,3,4-oxadiazole, carrying out in vivo insecticidal evaluation against Mythimna separata Walker at $1 \mathrm{mg} / \mathrm{mL}$ with compound (89) having a corrected mortality rate of $69.0 \%, 27 \%$ higher than the Toosendanin standard ${ }^{102}$. $\mathrm{Xu}$ and colleagues also synthesized trifluoromethyl pyridine analogues containing 1,3,4-oxadiazole moieties which displayed insecticidal activity against Mythimna separata, $P$. xylostella, $N$. lugens and $A$. craccivora with compound (90a) having the most potent activity against Mythimna separata with an $\mathrm{LC}_{50}$ value of $30.8 \mathrm{mg} / \mathrm{L}, 1.2$ points away from the Avermectin standard with insecticidal activity of $100 \%$ at $250 \mathrm{mg} / \mathrm{L}$ and compound (90b) showing highest activity against $P$. xylostella, $N$. lugens and $A$. craccivora with insecticidal activity of $100 \%$, $63 \%$ and $55 \%$ respectively at $500 \mathrm{mg} / \mathrm{L}$ for all the insects and also at $250 \mathrm{mg} / \mathrm{L}$ for $P$. xylostella ${ }^{103}$. Anthranilic diamides compounds synthesized by Liu and colleagues showed insecticidal activity against $P$. xylostella with compound (91a) exhibiting highest potency at $100 \%, 80.95 \%$ and $57.14 \%$ against $P$. xylostella at $40 \mu \mathrm{g} / \mathrm{mL}, 10 \mu \mathrm{g} / \mathrm{mL}$ and $4 \mu \mathrm{g} / \mathrm{mL}$ respectively ${ }^{104}$. The previous year, Li and coworkers also synthesized anthranilic diamides bearing 1,3,4oxadiazoles and compound (91b) showed the highest insecticidal activity exhibiting $71.43 \%$ mortality rate for P. xylostella at $0.4 \mu \mathrm{g} / \mathrm{mL}$ and $33.33 \%$ for $S$. exigua at $1 \mu \mathrm{g} / \mathrm{mL}^{105}$. 


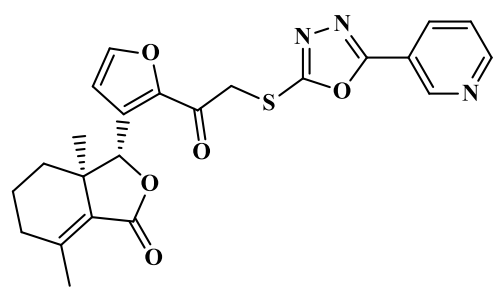

(88)

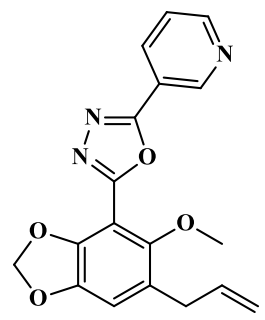

(89)<smiles>[R]c1nnc(-c2ncc(C(F)(F)F)cc2Cl)o1</smiles>

(90)

a: $\mathbf{R}=4$-fluorobenzyl

b: $\mathbf{R}=$ 5-Bromo-2-chlorophenyl

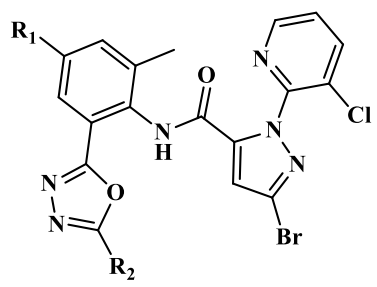

(91)

a: $R_{1}=B r, R_{2}=2$-pyrazyl

b: $R_{1}=C l, R_{2}=$ methylthio

Figure 13. Some 1,3,4-oxadiazole derivatives with insecticidal activity

\subsection{Anticonvulsant activity}

Epilepsy is amongst the most frequent neurological disorder, affecting about 50 million people worldwide. 1,3,4-oxadiazoles have been found to be potent anticonvulsant agents. Kumar and coworkers synthesized compounds containing 1,3,4-oxadiazole scaffold and evaluated for their anticonvulsant activity against maximal electroshock (MES) seizure; some of the compounds had promising activities like compound (92) showing a $67.53 \%$ protection with no neurotoxicity
106. Tabatabai and coworkers synthesized 1,3,4oxadiazole derivatives, evaluating for their potency as benzodiazepine receptor agonist, leading to possible anticonvulsant activities and compound (93) showed power, having $\mathrm{ED}_{50}$ of $206.64 \mu \mathrm{mol} / \mathrm{Kg}{ }^{107}$. Singh synthesized 1,3,4-oxadiazole containing compounds having significant anticonvulsant activity with compound (94) showing a with a mean convulsive threshold of $413.28 \%$ 108.

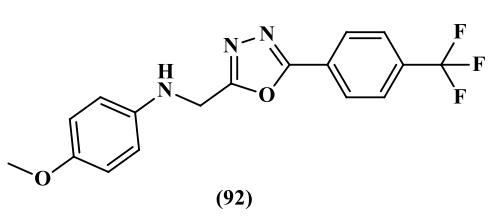

(92)

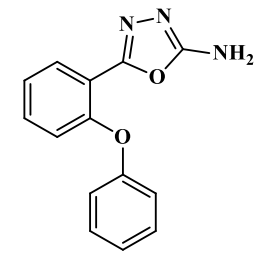

(93)

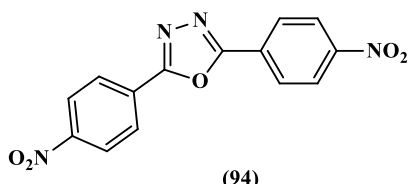

(94)

Figure 14. Some 1,3,4-oxadiazole derivatives with anticonvulsant activity

\subsection{Antidepressant activity}

Abnormal regulation of glycogen synthase kinase 3 beta (GSK $3 \beta$ ) has been implicated with the possibility of causing psychiatric disorders such depression 109,110; therefore the development of GSK $3 \beta$ inhibitors have been identified as possible antidepressants. Benzimidazole analogues containing 1,3,4-oxadiazole1,2,3-triazoles have been identified as possible GSK $3 \beta$ inhibitors, with compound (95) being the most significant in the library having effective inhibition and sub-micromolar $\mathrm{IC}_{50}$ value of $0.15 \mu \mathrm{M}$ also showing significant antidepressant activity when tested using the Tail suspension test (TST) and the Forced swim test (FST) ${ }^{111}$. Developing on this previous work, Tantray and coworkers synthesized benzimidazole lined-1,3,4oxadiazole carboxamides. They tested for their GSK $3 \beta$ inhibitory activity, and the results were even better than the previous work done with compound (96) giving $\mathrm{IC}_{50}$ value of $0.13 \mu \mathrm{M}$ displaying antidepressant-like potency ${ }^{112}$. Compound (97), as seen above, also showed antidepressant activity decreasing locomotor activity substantially ${ }^{108}$. 


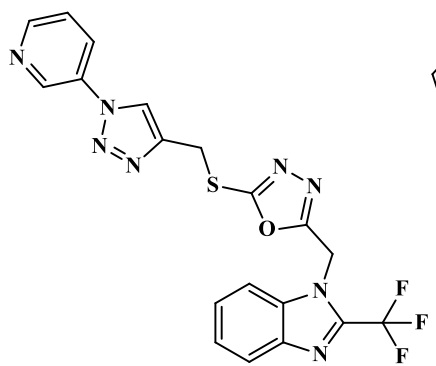

(95)

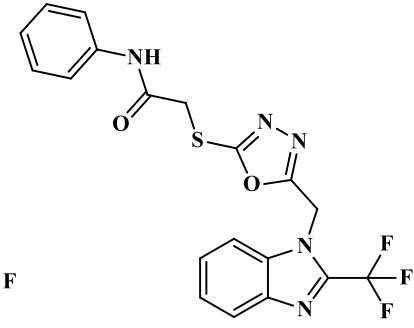

(96)

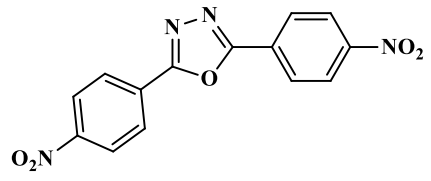

(97)

Figure 15. Some 1,3,4-oxadiazole derivatives with antidepressant activity

\subsection{Herbicidal activity}

1,3,4-oxadiazole derivatives which can serve as possible herbicides have emerged. ${ }^{113}$ synthesized novel 1,3,4-oxadiazoles with herbicidal activity; compound (98) had the highest activity amongst the synthesized oxadiazoles showing a $100 \%, 85 \%$ and $70 \%$ herbicidal<smiles>C[C@@H](Oc1ccc(Oc2ncc(Cl)cc2F)cc1)c1n[nH]c(=O)o1</smiles>

(98) activity against Echinochloa crussgalli, Avena fatua, Sorgum halepense with $0 \%$ damage to both barley and wheat. Sun and coworkers synthesized 1,3,4-oxadiazole compounds with herbicidal activity against Brassica campestris with compound (99) showing the significant activity of $50.6 \%$ at $10 \mu \mathrm{g} / \mathrm{mL}^{114}$.

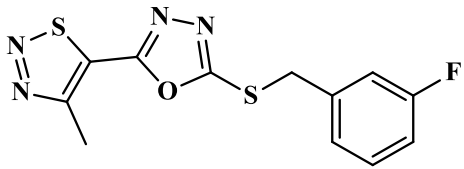

(99)

Figure 16. Some 1,3,4-oxadiazole derivatives with herbicidal activity

\subsection{Antioxidant activity}

Oxidative stress is caused by the damage of lipids, DNA, carbohydrates, and proteins as a result of the build-up of reactive oxygen species (ROS), which could ultimately lead to the death of cells ${ }^{115}$. Mihailović and coworkers synthesized eight 1,3,4-oxadiazole analogues, testing for their antioxidant activity by their capacity to scavenge stable 2,2-diphenyl-1picrylhydrazyl (DPPH) radicals; oxadiazole (100a) had the highest DPPH scavenging activity $\left(\mathrm{IC}_{50}=13.59\right.$ $\mu \mathrm{M})^{60}$. The further antioxidant analysis was undertaken, and such as the ABTS assay, ferric ion reducing capacity and $\mathrm{H}_{2} \mathrm{O}_{2}$ scavenging assays with compounds 100a $\left(\mathrm{IC}_{50}=79.3 \mu \mathrm{M} ; 3\right.$ times better than the ascorbic acid standard), $\mathbf{1 0 0 b}(0.27)$ and $\mathbf{1 4 4 c}\left(\mathrm{IC}_{50}\right.$ $=75.17 \mu \mathrm{M}$ ) being the most potent respectively in the oxadiazole series. Furthermore, compound 100c displayed the highest activity $\left(\mathrm{IC}_{50}=25.59 \mu \mathrm{M}\right)$ for protection against hydrogen peroxide-induced stress in normal lung fibroblasts MRC-5. Ünver and coworkers synthesized two bis-1,3,4-oxadiazole analogues having better antioxidant activity compared to both the butylated hydroxytoluene (BHT) and Trolox standard in the DPPH test with a ferric reducing power activity of 1010 and $1184 \mu \mathrm{mol} \mathrm{FeSO}_{4} \cdot 7 \mathrm{H}_{2} \mathrm{O}$ for (101a) and (101b) respectively in the ferric reducing antioxidant power (FRAP) assay ${ }^{116}$. Sauer and colleagues synthesized organosulfur analogues containing 1,3,4oxadiazole moieties, and compound (102) had the highest antioxidant property $\left(\mathrm{EC}_{50}=<10 \mu \mathrm{g} / \mathrm{mL}\right)$ on scavenging of DPPH activity, a promising activity higher than the BHT standard ${ }^{117}$. Other 1,3,4oxadiazoles having good scavenging activity on DPPH radical includes compounds $\left(\mathbf{1 0 3} ; \mathrm{IC}_{50}=19.62 \mu \mathrm{M}\right){ }^{118}$, $\left(\mathbf{1 0 4} ; \mathrm{IC}_{50}=16.35 \mu \mathrm{g} / \mathrm{mL}\right){ }^{119}$ and $(\mathbf{1 0 5} ; \%$ scavenging activity $=41.3 \%)$. 


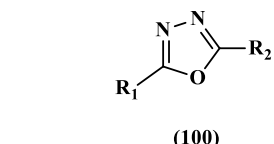

a: $\mathbf{R}_{1}=$ phenyl, $\mathbf{R}_{2}=$ 3,4-dihydroxyphenyl b: $R_{1}=2,3$-dihydroxyphenyl, $R_{2}=$ phenyl c: $R_{1}=3$,5-dihydroxyphenyl, $R_{2}=3$,4-dihydroxyphenyl

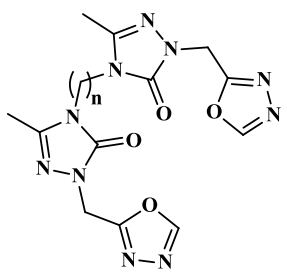

(101)

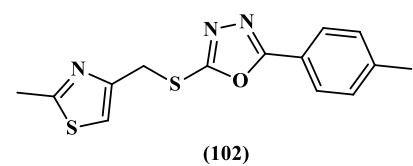

(102)

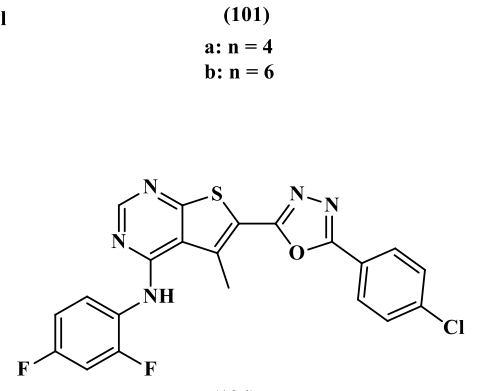

(104)

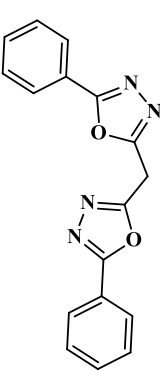

(105)

Figure 17. Some 1,3,4-oxadiazole derivatives with antioxidant activity

\subsection{Antileishmanial activity}

Over 350 million people are currently in danger of leishmaniasis, with a record of 2 million new cases annually, leading to the death of 51,000 people yearly; therefore the provision of treatment for the protozoan infection is ipso facto quintessential ${ }^{120}$. Gold (I) complexes with 1,3,4-oxadiazole moieties were synthesized, and after evaluation, they displayed significant selectivity against Leishmania infantum; compound (106) was the most selective against $L$. infantum with an $\mathrm{IC}_{50}$ value of $0.97 \mu \mathrm{M}{ }^{67}$. Similarly, Taha and coworkers synthesized phenyl linked oxadiazole moieties which showed antileishmanial activities with compound (107) being the most prominent, with $\mathrm{IC}_{50}$ of $0.95 \mu \mathrm{M}$ being 7 times more potent than the Pentamidine standard ${ }^{121}$. Compound (108) an oxadiazole derivative synthesized by ${ }^{122}$ was found to be about 70 times more potent as an antileishmanial agent than the standard drug with an $\mathrm{IC}_{50}$ of $0.10 \mu \mathrm{M}$.<smiles>CC[P+](CC)(CC)[As]c1nnc(-c2ccccc2)o1</smiles>

(106)<smiles>O=C(NNC(=S)Nc1ccc(C(F)(F)F)cc1)c1ccc(-c2nnc(-c3ccc4ncccc4c3)o2)cc1</smiles>

(108)

Figure 18. Some 1,3,4-oxadiazoles with antileishmanial activity

\subsection{Other enzyme inhibitory activities}

Compound (109) displayed potency against human cholinesterase, with $\mathrm{IC}_{50}$ for maximum hAChE to be $1.098 \mu \mathrm{M}$ and non-competitive type enzyme inhibition to be $\mathrm{Ki}=0.960 \mu \mathrm{M}^{33}$. These results showed that it could serve as potential Alzheimer's disease (AD). 1,3,4-oxadiazoles have been reported to inhibit $\mathrm{Ca}^{2+} /$ calmodulin-stimulated cyclic adenosine 3',5'monophosphate (cAMP) production in cells stably expressing with Adenylyl cyclases type 1 (AC1) and 8 (AC8), hence can serve as a potential treatment for chronic pain and opioid dependence; compound (110) 
was amongst the most active in the library with $\mathrm{IC}_{50}$ of 1.4 and 4.1 against AC1 and AC8 respectively ${ }^{123}$. Compound (111) showed noncompetitive inhibition against human acetylcholinesterase (hAChE), making it a possible treatment of cognitive disorders $\left(\mathrm{pIC}_{50}=6.52\right.$ $\mu \mathrm{M} ; \mathrm{Ki}=0.17 \mu \mathrm{M}){ }^{124}$. Compound (112) showed attractive thymidine phosphorylase (TP) inhibition, making it a potential antitumor agent having an $\mathrm{IC}_{50}$ value of $38.24 \mu \mathrm{M}$, even slightly better than the 7deazanthine (7DX) standard used ${ }^{125}$.<smiles>Oc1ccc(-c2nnc(Nc3ccncc3)o2)cc1</smiles>

(109)

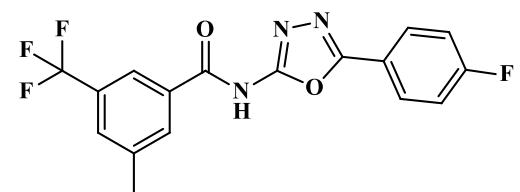

(110)

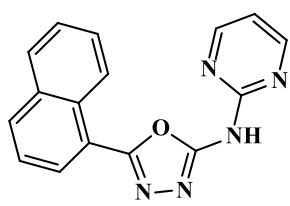

(111)<smiles>Oc1ccc(-c2n[nH]c(=S)o2)cc1</smiles>

(112)

Figure 19. Some selected 1,3,4-oxadiazole derivatives having inhibitory enzyme activities

\section{Discussion}

1,3,4-oxadiazole is proving to be a very interesting and versatile synthetic scaffold with the availability of various viable and straightforward synthetic pathways, ranging from cyclization of hydrazides to the electrolysis of hydrazones.

1,3,4-oxadiazole derivatives have also shown their vast potential in drug development and medicinal chemistry, have potency against various diseases such as malaria, fungal infections, HIV, tumour/cancer, bacterial infections and many others.

\section{Conclusion}

1,3,4-oxadiazoles are an important class of heterocyclic compounds. 1,3,4-oxadiazole derivatives have already been utilized in the synthesis of known drugs and would most likely continue to be used in effective drug synthesis, owing to the numerous viable and green synthetic methods available. This review therefore, shows the numerous pathways and immense importance of the 1,3,4-oxadiazole scaffold.

\section{Acknowledgement}

The authors gratefully acknowledged Covenant University for her support.

\section{References}

1- V. D. Aderohunmu, T. T. Odutola, O. O. Ajani, E. F. Adebiyi, Tosmic reagent: an excellent precursor in the synthesis of biologically active heterocycles, Rasayan J. Chem., 2019, 12,
1919-1926.

2- O. O. Ajani, J. T. Isaac, T. F. Owoeye, A. A. Akinsiku, Exploration of the chemistry and biological properties of pyrimidine as a privilege pharmacophore in therapeutics, Int. J. Biol. Chem., 2015, 9, 148-177.

3- X. F. Shang, Z. M. Zhao, J. C. Li, G. Z. Yang, Y. Q. Liu, L. X. Dai, Insecticidal and antifungal activities of Rheum palmatum L. anthraquinones and structurally related compounds, Ind. Crops Prod., 2019, 137, 508-520.

4- S. A. Mayank, N. Kaur, N. Garg, N. Singh, Anticancer SAR establishment and novel accruing signal transduction model of drug action using biscoumarin scaffold, Comput. Biol. Chem., 2019, 83, 107104.

5- W. T. Wang, H. Qian, J. W. Wu, X. W. Chen, J. Q. $\mathrm{Li}$, Synthesis and antidepressant-like activity of novel alkoxy-piperidine derivatives targeting SSRI/5-HT1A/5-HT7, Bioorg. Med. Chem. Lett., 2019, 29, 126769.

6- L. Huang, J. Ding, M. Li, Z. Hou, Y. Geng, X. Li, Discovery of $[1,2,4]$-triazolo [1,5-a]pyrimidine$7(4 \mathrm{H})$-one derivatives as positive modulators of GABAA1 receptor with potent anticonvulsant activity and low toxicity, Eur. J. Med. Chem., 2019, 111824. http://dx.doi.org/10.1016/J.EJMECH.2019.111824.

7- X. M. Chu, C. Wang, W. L. Wang, L. L Liang, W. Liu, K. K. Gong, Triazole derivatives and their antiplasmodial and antimalarial activities, Eur. J. Med. Chem., 2019, 166, 206-223.

8- P. Pitasse-Santos, V. Sueth-Santiago, M. E. F. 
Lima, 1,2,4- and 1,3,4-Oxadiazoles As Scaffolds in the Development of Antiparasitic Agents, J. Braz. Chem. Soc., 2018, 29, 435-456.

9- M. Carbone, Y. Li, C. Irace, E. Mollo, F. Castelluccio, A. Di Pascale, Structure and cytotoxicity of phidianidines A and B: First finding of 1,2,4-oxadiazole system in a marine natural product, Org. Lett., 2011, 13, 2516-2519.

10-J. T. Brogan, S. L. Stoops, C. W. Lindsley, Total synthesis and biological evaluation of phidianidines $\mathrm{a}$ and $\mathrm{b}$ uncovers unique pharmacological profiles at CNS targets, ACS Chem. Neurosci., 2012, 3, 658-664.

11-W. Caneschi, K. B. Enes, C. Carvalho de Mendonça, F. de Souza Fernandes, F. B. Miguel, J. M. da Silva, Synthesis and anticancer evaluation of new lipophilic 1,2,4 and 1,3,4-oxadiazoles, Eur. J. Med. Chem., 2019, 165, 18-30.

12-X. Song, P. Li, M. Li, A. Yang, L. Yu, L. Luo, Synthesis and investigation of the antibacterial activity and action mechanism of 1,3,4-oxadiazole thioether derivatives, Pestic. Biochem. Physiol., 2018, 147, 11-19.

13-A. Zumla, A. George, V. Sharma, R. H. N. Herbert, A. Oxley, M. Oliver, The WHO 2014 Global tuberculosis report-further to go, Lancet Glob. Heal., 2015, 3, e10-e12.

14-S. A. Popov, M. D. Semenova, D. S. Baev, I. V. Sorokina, N. A. Zhukova, T. S. Frolova, Lupanetype conjugates with aminoacids, 1,3,4- oxadiazole and 1,2,5-oxadiazole-2-oxide derivatives: Synthesis, anti-inflammatory activity and in silico evaluation of target affinity, Steroids, 2019, 150, 108443.

15-X. Gan, D. Hu, Z. Chen, Y. Wang, B. Song, Synthesis and antiviral evaluation of novel 1,3,4oxadiazole/thiadiazole-chalcone conjugates, Bioorg. Med. Chem. Lett, 2017, 27, 4298-4301.

16-Y. Zhang, C. Zuniga, S. J. Kim, D. Cai, S. Barlow, S. Salman, Polymers with carbazole-oxadiazole side chains as ambipolar hosts for phosphorescent light-emitting diodes, Chem. Mater., 2011, 23, 4002-4015.

17-A. Bruno, C. Borriello, T. Di Luccio, L. Sessa, S. Concilio, S. A. Haque, Oxadiazole-carbazole polymer (POC)-Ir(ppy)3 tunable emitting composites, Opt. Mater. (Amst), 2017, 66, 166-170.

18-D. Zhang, X. Hua, M. Liu, C. Wu, W. Wei, Y. Liu, Design, synthesis and herbicidal activity of novel sulfonylureas containing triazole and oxadiazole moieties, Chem. Res. Chinese Univ., 2016, 32, 607-614.

19-P. A. Rugmini, M. Prajila, A. Joseph, Effect of substitution and temperature on the corrosion inhibition properties of benzimidazole bearing 1, 3, 4-oxadiazoles for mild steel in sulphuric acid: Physicochemical and theoretical studies, J. Environ. Chem. Eng., 2018, 6, 1072-1085.

20-M. Bouanis, M. Tourabi, A. Nyassi, A. Zarrouk, C. Jama, F. Bentiss, Corrosion inhibition performance of 2,5-bis(4-dimethylaminophenyl)1,3,4-oxadiazole for carbon steel in $\mathrm{HCl}$ solution: Gravimetric, electrochemical and XPS studies, Appl. Surf. Sci., 2016, 389, 952-966.

21-R. Sharma, N. Kumar, R. Yaday, Chemistry and Pharmacological Importance of 1,3,4-oxadiazole Derivatives, Res. Rev. J. Chem., 2015, 4, 1-27.

22-Nagaraj, K. C. Chaluvaraju, M. S. Niranjan, S. Kiran. 1, 3, 4 Oxadiazole a Potent Drug Candidate With Various Pharmacological Activities, Int. J. Pharm. Pharm. Sci., 2011, 3, 9-16.

23-S. Sharma, P. K. Sharma, N. Kumar, R. Dudhe, Chemistry and pharmacological potentials of Oxadiazoles: A Review, Der Pharma Chem., 2010, 2, 253-263.

24-A. D. M. Curtis, N. Jennings, 1,2,4-Triazoles. Compr. Heterocycl, Chem. 2008, 3, 159-209. http://dx.doi.org/10.1016/B978-008044992$0.00502-2$

25-A. Almasirad, S. A. Tabatabai, M. Faizi, A. Kebriaeezadeh, N. Mehrabi, A. Dalvandi, Synthesis and anticonvulsant activity of new 2-substituted-5- [2-(2-fluorophenoxy)phenyl]1,3,4-oxadiazoles and 1,2,4-triazoles, Bioorg. Med. Chem. Lett., 2004, 14, 6057-6059.

26-A. Kakefuda, T. Suzuki, T. Tobe, A. Tahara, S. Sakamoto, S. Tsukamoto, Discovery of 4,5Diphenyl-1,2,4-triazole Derivatives as a Novel Class of Selective Antagonists for the Human V1A Receptor, Bioorg. Med. Chem., 2002, 10, 1905-1912.

27-S. A. Khanum, S. Shashikanth, S. Umesha, R. Kavitha, Synthesis and antimicrobial study of novel heterocyclic compounds from hydroxybenzophenones, Eur. J. Med. Chem., 2005, 40, 1156-1162.

28-Y. Nagao, T. Hirata, S. Goto, S. Sano, A. Kakehi, K. Lizuka, Intramolecular nonbonded S ..O interaction recognized in (acylimino)thiadiazoline derivatives as angiotensin II receptor antagonists and related compounds, J. Am. Chem. Soc., 1998, 120, 3104-3110.

29-M. R. Grimmett, I. Brian, Synthesis and Reactions of lithiated monocyclic azoles containing two or more hetero-atoms. Part vi: Triazoles, tetrazoles, oxadiazoles, and thiadiazoles, Heterocycles, 1995, 41, 1525-1574. http://dx.doi.org/10.3987/REV-95468.

30-K. Ohmoto, T. Yamamoto, M. Okuma, T. Horiuchi, H. Imanishi, Y. Odagaki, 
Development of orally active nonpeptidic inhibitors of human neutrophil elastase, J. Med. Chem., 2001, 44, 1268-1285.

31-A. A. Tolmachev, E. V. Zarudnitskii, A. A. Yurchenko, A. M. Pinchuk, Phosphorylation of 2-phenyl-1,3,4-oxadiazole with phosphorus (III) halides, Chem. Heterocycl. Compd., 1999, 35, 1117-1119.

32-S. G. Narella, M. G. Shaik, A. Mohammed, M. Alvala, A. Angeli, C. T. Supuran, Synthesis and biological evaluation of coumarin-1,3,4-oxadiazole hybrids as selective carbonic anhydrase IX and XII inhibitors, Bioorg. Chem., 2019, 87, 765-772.

33-P. Mishra, P. Sharma, P. N. Tripathi, S. K. Gupta, P. Srivastava, A. Seth, Design and development of 1,3,4-oxadiazole derivatives as potential inhibitors of acetylcholinesterase to ameliorate scopolamineinduced cognitive dysfunctions, Bioorg. Chem., 2019, 89, 103025.

34-K. Lakshmithendral, K. Saravanan, R. Elancheran, K. Archana, N. Manikandan, H. A. Arjun, Design, synthesis and biological evaluation of 2-(phenoxymethyl)-5-phenyl-1,3,4-oxadiazole derivatives as anti-breast cancer agents, Eur. J. Med. Chem., 2019, 168, 1-10.

35-S. Bala, S. Kamboj, A. Kajal, V. Saini, D. N. Prasad, Antimicrobial Potential, and Computational Studies, Biomed Res, Int., 2014.

36-Q. Gao, S. Liu, X. Wu, J. Zhang, A. Wu, Direct Annulation of Hydrazides to 1,3,4-Oxadiazoles via Oxidative C(CO)-C(Methyl) Bond Cleavage of Methyl Ketones, Org. Lett., 2015, 17, 2960-2963.

37-Y. Fan, Y. He, X. Liu, T. Hu, H. Ma, X. Yang, Iodine-Mediated Domino Oxidative Cyclization: One-Pot Synthesis of 1,3,4-Oxadiazoles via Oxidative Cleavage of $\mathrm{C}(\mathrm{sp} 2)-\mathrm{H}$ or $\mathrm{C}(\mathrm{sp})-\mathrm{H}$ Bond, J. Org. Chem., 2016, 81, 6820-6825.

38-A. Kudelko, K. Jasiak, K. Ejsmont, Study on the synthesis of novel 5-substituted 2-[2-(pyridyl)ethenyl]-1,3,4-oxadiazoles and their acid-base interactions, Monatshefte fur Chemie., 2015, 146, 303-311.

39-G. Prabhu, V. V. Sureshbabu, Hypervalent iodine $(\mathrm{V})$ mediated mild and convenient synthesis of substituted 2-amino-1,3,4-oxadiazoles, Tetrahedron Lett., 2012, 53, 4232-4234.

40-T. Fang, Q. Tan, Z. Ding, B. Liu, B. Xu, PdCatalyzed Oxidative Annulation of Hydrazides with Isocyanides: Synthesis of 2-Amino-1,3,4oxadiazoles, Org. Lett., 2014, 16, 2342-2345.

41-S. N. R. Mule, S. K. Battula, G. Velupula, D. R. Guda, H. B. Bollikolla, 10-Camphorsulfonic acid $(( \pm)-C S A)$ catalyzed facile one-pot synthesis of a new class of 2,5-disubstituted 1,3,4-oxadiazoles, RSC Adv., 2014, 4, 58397-58403.

42-F. Yu, A. Guan, M. Li, L. Hu, X. Li, Design, synthesis, and fungicidal activity of novel 1,3,4oxadiazole derivatives, Chinese Chem. Lett., 2018, 29, 915-918.

43-B. Koçyiğit-Kaymakçığlu, E. E. Oruç-Emre, S. Ünsalan, N. Tabanca, S. I. Khan, D. E. Wedge, Synthesis and biological activity of hydrazidehydrazones and their corresponding 3-Acetyl-2,5disubstituted-2,3-dihydro-1,3,4-oxadiazoles, Med. Chem. Res., 2012, 21, 3499-3508.

44-L. Zhang, X. Zhao, X. Jing, X. Zhang, S. Lü, L. Luo, Oxidation of sp3 $\mathrm{CH}$ bonds in $\mathrm{N}$ alkylhydrazides: Access to 2,5-disubstituted 1,3,4oxadiazole derivatives, Tetrahedron Lett., 2016, 57, 5669-5672.

45-G. Zhang, Y. Yu, Y. Zhao, X. Xie, C. Ding, Iron(III)/TEMPO-Catalyzed Synthesis of 2,5-Disubstituted 1,3,4-Oxadiazoles by Oxidative Cyclization under Mild Conditions, Synlett, 2017, 28, 1373-1377.

46-G. Majji, S. K. Rout, S. Guin, A. Gogoi, B. K. Patel, Iodine-catalysed oxidative cyclisation of acylhydrazones to 2,5-substituted 1,3,4oxadiazoles, RSC Adv., 2014, 4, 5357-5362.

47-S. J. Yang, S. H. Lee, H. J. Kwak, Y. D. Gong. Regioselective Synthesis of 2-Amino-Substituted 1,3,4-Oxadiazole and 1,3,4-Thiadiazole Derivatives via Reagent-Based Cyclization of Thiosemicarbazide Intermediate, J. Org. Chem, 2013, 78, 438-444.

48-S. Maghari, S. Ramezanpour, F. Darvish, S. Balalaie, F. Rominger, H. R. Bijanzandeh, A new and efficient synthesis of 1,3,4-oxadiazole derivatives using TBTU, Tetrahedron, 2013, 69, 2075-2080.

49-S. J. Yang, J. H. Choe, A. Abdildinova, Y. D. Gong, A Highly Efficient Diversification of 2-Amino/Amido-1,3,4-oxadiazole and 1,3,4Thiadiazole Derivatives via Reagent-Based Cyclization of Thiosemicarbazide Intermediate on Solid-Phase ACS Comb. Sci., 2015, 17, 732-741.

50-A. Abdildinova, S. J. Yang, Y. D. Gong. Solidphase parallel synthesis of 1,3,4-oxadiazole based peptidomimetic library as a potential modulator of protein-protein interactions, Tetrahedron, 2018, 74, 684-691.

51-M. A. Rahman, M. R. Karim, M. Arifuzzaman, T. A. Siddiquee, A. H. Mirza, $\mathrm{ZnCl} 2$ catalyzed efficient synthesis of 1,3,4-oxadiazole and 1,3,4thiadiazole, Tetrahedron Lett., 2014, 55, 3267-3273.

52-Y. Xie, J. Liu, P. Yang, X. Shi, J. Li, Synthesis of 2-amino-1,3,4-oxadiazoles from isoselenocyanates via cyclodeselenization, Tetrahedron, 2011, 67, 5369-5374.

53-L. Santhosh, C. Srinivasulu, S. Durgamma, G. Prabhu, V. V. Sureshbabu, Facile one-pot synthesis 
of 2-amino-1,3,4-oxadiazole tethered peptidomimetics by molecular-iodine-mediated cyclodeselenization, New J. Chem., 2017, 41, 11225-11229.

54-M. Rouhani, A. Ramazani, S. W. Joo, Novel, fast and efficient one-pot sonochemical synthesis of 2-aryl-1,3,4-oxadiazoles, Ultrason. Sonochem., 2014, 21, 262-267.

55-M. Rouhani, A. Ramazani, S. W. Joo, Ultrasonics in isocyanide-based multicomponent reactions: A new, efficient and fast method for the synthesis of fully substituted 1,3,4-oxadiazole derivatives under ultrasound irradiation, Ultrason. Sonochem., 2015, 22, 391-396.

56-A. K. Yadav, L. D. S. Yadav, Visible-lightpromoted aerobic oxidative cyclization to access 1,3,4-oxadiazoles from aldehydes and acylhydrazides, Tetrahedron Lett., 2014, 55, 2065-2069.

57-P. Diao, Y. Ge, W. Zhang, C. Xu, N. Zhang, C. Guo, Synthesis of 2,5-disubstituted 1,3,4oxadiazoles by visible-light-mediated decarboxylation-cyclization of hydrazides and diketones, Tetrahedron Lett., 2018, 59, 767-770.

58-L. Wang, Y. Wang, Q. Chen, M. He, Photocatalyzed facile synthesis of 2,5-diaryl 1,3,4oxadiazoles with polyaniline- $\mathrm{g}-\mathrm{C}_{3} \mathrm{~N}_{4}-\mathrm{TiO}_{2}$ composite under visible light, Tetrahedron Lett., 2018, 59, 1489-1492.

59-P. Stabile, A. Lamonica, A. Ribecai, D. Castoldi, G. Guercio, O. Curcuruto, Mild and convenient one-pot synthesis of 1,3,4-oxadiazoles, Tetrahedron Lett., 2010, 51, 4801-4805.

60-N. Mihailović, V. Marković, I. Z. Matić, N. S. Stanisavljević, Ž. S. Jovanović, S. Trifunović, Synthesis and antioxidant activity of 1,3,4oxadiazoles and their diacylhydrazine precursors derived from phenolic acids, RSC Adv., 2017, 7, 8550-8560.

61-S. Wet-osot, W. Phakhodee, M. Pattarawarapan, Application of N-Acylbenzotriazoles in the Synthesis of 5-Substituted 2-Ethoxy-1,3,4oxadiazoles as Building Blocks toward 3,5Disubstituted 1,3,4-Oxadiazol-2(3H)-ones, J. Org. Chem., 2017, 82, 9923-9929.

62-C. X. Guo, W. Z. Zhang, N. Zhang, X. B. Lu, 1,3Dipolar Cycloaddition of Nitrile Imine with Carbon Dioxide: Access to 1,3,4-Oxadiazole2(3H)-ones, J. Org. Chem., 2017, 82, 7637-7642.

63-L. Wang, J. Cao, Q. Chen, M. He, One-Pot Synthesis of 2,5-Diaryl 1,3,4-Oxadiazoles via Ditert-butyl Peroxide Promoted N-Acylation of Aryl Tetrazoles with Aldehydes, J. Org. Chem., 2015, 80, 4743-4748.

64-N. C. Desai, H. Somani, A. Trivedi, K. Bhatt, L. Nawale, V. M. Khedkar, Synthesis, biological evaluation and molecular docking study of some novel indole and pyridine based 1,3,4-oxadiazole derivatives as potential antitubercular agents, Bioorg. Med. Chem. Lett., 2016, 26, 1776-1783.

65-S. Singh, L. K. Sharma, A. Saraswat, I. R. Siddiqui, H. K. Kehri, R. K. P. Singh, Electrosynthesis and screening of novel 1,3,4oxadiazoles as potent and selective antifungal agents, RSC Adv., 2013, 3, 4237-4245.

66-S. Bajaj, P. P. Roy, J. Singh, Synthesis, thymidine phosphorylase inhibitory and computational study of novel 1,3,4-oxadiazole-2-thione derivatives as potential anticancer agents, Comput. Biol. Chem., 2018, 76, 151-160.

67-J. D. S. Chaves, L. G. Tunes, C. H. Franco, T. M. Francisco, C. C. Corrêa, S. M. F. Murta, Novel gold(I) complexes with 5-phenyl-1,3,4-oxadiazole2-thione and phosphine as potential anticancer and antileishmanial agents, Eur. J. Med. Chem., 2017, 127, 727-739.

68-V. Nieddu, G. Pinna, I. Marchesi, L. Sanna, B. Asproni, G. A. Pinna, Synthesis and Antineoplastic Evaluation of Novel Unsymmetrical 1,3,4-Oxadiazoles, J. Med. Chem., 2016, 59, 10451-10469.

69-B. Mochona, X. Qi, S. Euynni, D. Sikazwi, N. Mateeva, K. F. Soliman, Design and evaluation of novel oxadiazole derivatives as potential prostate cancer agents, Bioorg. Med. Chem. Lett., 2016, 26, 2847-2851.

70-E. M. M. Gamal, M. I. El-Gamal, M. S. AbdelMaksoud, K. H. Yoo, C. H. Oh, Synthesis and in vitro antiproliferative activity of new 1,3,4oxadiazole derivatives possessing sulfonamide moiety, Eur. J. Med. Chem., 2015, 90, 45-52.

71-A. V. R. Subba, V. Vishnu, R. N. V. Subba, R. T. Srinivasa, S. P. Shaik, C. Bagul, Synthesis and biological evaluation of imidazopyridinyl-1,3,4oxadiazole conjugates as apoptosis inducers and topoisomerase II $\alpha$ inhibitors, Bioorg. Chem., 2016, 69, 7-19.

72-N. J. P. Subhashini, B. Bhadraiah, P. Janaki, Synthesis and biological evaluation of 1,3,4oxadiazole fused pyridine derivatives as antibacterial and antifungal agents, Russ. J. Gen. Chem., 2017, 87, 550-553.

73-G. A. Ç. Karaburun, G. B. K. Çavuşo, U. A. Çevik, D. Osmaniye, G. B. N. Sa, S. Levant, Synthesis and antifungal potential of some novel benzimidazole-1,3,4-oxadiazole compounds, Molecules, 2019, 24, 1-14.

74-X. Wang, H. Hu, X. Zhao, M. Chen, T. Zhang, C. Geng, Novel quinazolin-4(3H)-one derivatives containing a 1,3,4-oxadiazole thioether moiety as potential bactericides and fungicides: Design, synthesis, characterization and 3D-QSAR analysis, 
J. Saudi Chem. Soc., 2019. doi:10.1016/J.JSCS.2019.07.006

75-J. Dai, W. Dan, S. Ren, C. Shang, J. Wang, Design, synthesis and biological evaluations of quaternization harman analogues as potential antibacterial agents, Eur. J. Med. Chem., 2018, 160, 23-36.

76-X. Hua, Q. Yang, W. Zhang, Z. Dong, S. Yu, S. Schwarz, Antibacterial Activity and Mechanism of Action of Aspidinol Against Multi-DrugResistant Methicillin-Resistant Staphylococcus aureus, Front. Pharmacol., 2018, 9.

77-Y. Guo, T. Xu, C. Bao, Z. Liu, J. Fan, R. Yang, Design and synthesis of new norfloxacin-1,3,4oxadiazole hybrids as antibacterial agents against methicillin-resistant Staphylococcus aureus (MRSA), Eur. J. Pharm. Sci., 2019, 136, 104966.

78-N. N. Farshori, A. Rauf, M. A. Siddiqui, E. S. AlSheddi, M. M. Al-Oqail, A facile one-pot synthesis of novel 2,5-disubstituted-1,3,4-oxadiazoles under conventional and microwave conditions and evaluation of their in vitro antimicrobial activities, Arab. J. Chem., 2017, 10, S2853-S2861.

79-Beena, D. S. Rawat, Antituberculosis Drug Research: A Critical Overview. Med. Res. Rev., 2013, 33, 693-764.

80-T. Kaneko, C. Cooper, K. Mdluli, Challenges and opportunities in developing novel drugs for TB, Future Med. Chem., 2011, 3, 1373-1400.

81-U. Sharma, Current possibilities and unresolved issues of drug target validation in Mycobacterium tuberculosis, Expert Opin. Drug Discov., 2011, 6, 1171-1186.

82-S. T. Dhumal, A. R. Deshmukh, M. R. Bhosle, V. M. Khedkar, L. U. Nawale, D. Sarkar, Synthesis and antitubercular activity of new 1,3,4oxadiazoles bearing pyridyl and thiazolyl scaffolds, Bioorg. Med. Chem. Lett., 2016, 26, 3646-3651.

83-A. N. Ambhore, S. S. Kamble, S. N. Kadam, R. D. Kamble, M. J. Hebade, S. V. Hese, Design, synthesis and in silico study of pyridine based 1,3,4-oxadiazole embedded hydrazinecarbothioamide derivatives as potent anti-tubercular agent, Comput. Biol. Chem., 2019, 80, 54-65.

84-G. Karabanovich, J. Němeček, L. Valášková, A. Carazo, K. Konečná, J. Stolaříková, S-substituted 3,5-dinitrophenyl 1,3,4-oxadiazole-2thiols and tetrazole-5-thiols as highly efficient antitubercular agents, Eur. J. Med. Chem., 2017, 126, 369-383.

85-H. S. Abd-Ellah, M. Abdel-Aziz, M. E. Shoman, E. A. M Beshr, T. Kaoud, A. S. F. F. Ahmed, New 1,3,4-oxadiazole/oxime hybrids: Design, synthesis, anti-inflammatory, COX inhibitory activities and ulcerogenic liability, Bioorg. Chem., 2017, 74,
$15-29$.

86-H. S. Abd-Ellah, M. Abdel-Aziz, M. E. Shoman, E. A. M, Beshr, T. S. Kaoud, A. S. F. F. Ahmed, Novel 1,3,4-oxadiazole/oxime hybrids: Synthesis, docking studies and investigation of antiinflammatory, ulcerogenic liability and analgesic activities, Bioorg. Chem., 2016, 69, 48-63.

87-A. G. Banerjee, N. Das, S. A. Shengule, R. S. Srivastava, S. K. Shrivastava, Synthesis, characterization, evaluation and molecular dynamics studies of 5, 6-diphenyl-1,2,4-triazin$3(2 \mathrm{H})$-one derivatives bearing 5-substituted 1,3,4oxadiazole as potential anti-inflammatory and analgesic agents, Eur. J. Med. Chem., 2015, 101, 81-95.

88-C. R. Biju, K. Ilango, M. Prathap, K. Rekha, Design and Microwave-assisted Synthesis of 1,3,4Oxadiazole Derivatives for Analgesie and Antiinflammatory Activity, J. Young Pharm., 2012, 4, 33-37.

89-S. S. Thakkar, P. Thakor, H. Doshi, A. Ray, 1,2,4Triazole and 1,3,4-oxadiazole analogues: Synthesis, MO studies, in silico molecular docking studies, antimalarial as DHFR inhibitor and antimicrobial activities, Bioorg. Med. Chem., 2017, 25, 4064-4075.

90-G. Verma, M. F. Khan, L. N. Mohan, M. Ishaq, M. Akhter, A. Bakht, Targeting malaria and leishmaniasis: Synthesis and pharmacological evaluation of novel pyrazole-1,3,4-oxadiazole hybrids, Part II, Bioorg. Chem., 2019, 89, 102986.

91-G. G. Ladani, M. P. Patel, Novel 1,3,4-oxadiazole motifs bearing a quinoline nucleus: synthesis, characterization and biological evaluation of their antimicrobial, antitubercular, antimalarial and cytotoxic activities, New J. Chem., 2015, 39, 9848-9857.

92-S. K. Avula, A. Khan, N. U. Rehman, M. U. Anwar, Z. Al-Abri, A. Wadood, Synthesis of $1 \mathrm{H}-$ 1,2,3-triazole derivatives as new $\alpha$-glucosidase inhibitors and their molecular docking studies, Bioorg. Chem., 2018, 81, 98-106.

93-M. J. Naim, M. J. Alam, F. Nawaz, V. G. M. Naidu, S. Aaghaz, M. Sahu, Synthesis, molecular docking and anti-diabetic evaluation of 2,4thiazolidinedione based amide derivatives, Bioorg. Chem., 2017, 73, 24-36.

94-M. J. Naim, O. Alam, M. J. Alam, M. Q. Hassan, N. Siddiqui, V. G. M. Naidu, Design, synthesis and molecular docking of thiazolidinedione based benzene sulphonamide derivatives containing pyrazole core as potential anti-diabetic agents, Bioorg. Chem., 2018, 76, 98-112.

95-R. Bhutani, D. Pathak, G. Kapoor, A. Husain, M. A. Iqbal, Novel hybrids of benzothiazole-1,3,4oxadiazole-4-thiazolidinone: Synthesis, in silico 
ADME study, molecular docking and in vivo antidiabetic assessment, Bioorg. Chem., 2019, 83, 6-19.

96-P. C. Shyma, B. Kalluraya, S. K. Peethambar, A. M. Vijesh, Synthesis, characterization, antidiabetic and antioxidant activity of 1,3,4oxadiazole derivatives bearing 6-methyl pyridine moiety, Der Pharma Chem., 2015, 7, 137-145.

97-S. Kumar, D. S. Rathore, G. Garg, K. Khatri, R. Saxena, S. K. Sahu, Synthesis and evaluation of some 2-((benzothiazol-2-ylthio) methyl)-5-phenyl1, 3, 4-oxadiazole derivatives as antidiabetic agents, Asian Pacific J. Heal. Sci., 2017, 3, 65-74.

98-W. A. El-Sayed, F. A. El-Essawy, O. M. Ali, B. S. Nasr, M. M. Abdalla, A. A. H. Abdel-Rahman, Anti-HIV Activity of New Substituted 1,3,4Oxadiazole Derivatives and their Acyclic Nucleoside Analogues, Zeitschrift für Naturforsch., 2009, 64c, 773-778.

99-W. Wu, Q. Chen, A. Tai, G. Jiang, G. Ouyang, Synthesis and antiviral activity of 2-substituted methylthio-5-(4-amino-2-methylpyrimidin-5-yl)1,3,4-oxadiazole derivatives, Bioorg. Med. Chem. Lett., 2015, 25, 2243-2246.

100-T. M. C. Tan, Y. Chen, K. H. Kong, J, Bai, Y. Li, S. G. Lim, Synthesis and the biological evaluation of 2-benzenesulfonylalkyl-5-substituted-sulfanyl$[1,3,4]$-oxadiazoles as potential anti-hepatitis B virus agents, Antiviral Res., 2006, 71, 7-14.

101-M. Ding, J. Fan, Q. Zhang, X. Wang, Y. Zhao, M. Huang, Semisynthesis and insecticidal activity of some novel fraxinellone-based thioethers containing 1,3,4-oxadiazole moiety, R. Soc. Open Sci., 2017, 4, 171053.

102-Y. Guo, L. Qu, X. Wang, M. Huang, L. Jia, Y. Zhang, Iodine-catalyzed oxidative cyclisation for the synthesis of sarisan analogues containing 1,3,4-oxadiazole as insecticidal agents, RSC Adv., 2016, 6, 93505-93510.

103-F. Z. Xu, Y .Y. Wang, D. X. Luo, G. Yu, S. X. Guo, H. Fu, Design, synthesis, insecticidal activity and 3D-QSR study for novel trifluoromethyl pyridine derivatives containing an 1,3,4-oxadiazole moiety, RSC Adv., 2018, 8, 6306-6314.

104-Q. Liu, K. Chen, Q. Wang, J. Ni, Y. Li, H. Zhu, Synthesis, insecticidal activity, structure-activity relationship (SAR) and density functional theory (DFT) of novel anthranilic diamides analogs containing 1,3,4-oxadiazole rings, RSC Adv., 2014, 4, 55445-55451.

105-Y. Li, H. Zhu, K. Chen, R. Liu, A. Khallaf, $X$. Zhang, Synthesis, insecticidal activity, and structure-activity relationship (SAR) of anthranilic diamides analogs containing oxadiazole rings, Org. Biomol. Chem., 2013, 11, 3979-3988.

106-B. N. P. Kumar, K. N. Mohana, L. Mallesha,
Synthesis of N-[\{5-Aryl-1,3,4-oxadiazole-2yl \}methyl]-4-methoxyaniline Derivatives and Their Anticonvulsant Activity, Hindawi Publ. Corp. J. Chem., 2013, 2013, 1-8.

107-S. A. Tabatabai, S. Lashkari, M. Zarrindast, M. Gholinbeikian, A. Shafiee, Design, Synthesis and Anticonvulsant Activity of 2- (2-Phenoxy ) phenyl-1,3,4-oxadiazole Derivatives, Iran. J. Pharm. Res., 2013, 12, 105-111.

108-P. Singh, P. K. Sharma, J. K. Sharma, A. Upadhyay, N. Kumar, Synthesis and evaluation of substituted diphenyl-1,3,4-oxadiazole derivatives for central nervous system depressant activity, Org. Med. Chem. Lett., 2012, 2, 8.

109-M. Pardo, E. Abrial, R. S. Jope, E. Beurel, GSK3 $\beta$ isoform-selective regulation of depression, memory and hippocampal cell proliferation, Genes, Brain Behav., 2016, 15, 348-355.

110-E. J. Crofton, M. N. Nenov, Y. Zhang, F. Scala, S. A. Page, D. L. McCue, Glycogen synthase kinase 3 beta alters anxiety-, depression-, and addiction-related behaviors and neuronal activity in the nucleus accumbens shell, Neuropharmacology, 2017, 117, 49-60.

111-M. A. Tantray, I. Khan, H. Hamid, M. S. Dhulap, A. Kalam, Synthesis of benzimidazole-based 1,3,4oxadiazole-1,2,3-triazole conjugates as glycogen synthase kinase-3 $\beta$ inhibitors with antidepressant activity in in vivo models, RSC Adv., 2016, 6, 43345-43355.

112-M. A. Tantray, I. Khan, H. Hamid, M. S. Alam, A. Dhulap, A. Kalam, Synthesis of benzimidazolelinked-1,3,4-oxadiazole carboxamides as GSK-3 $\beta$ inhibitors with in vivo antidepressant activity. Bioorg. Chem., 2018, 77, 393-401.

113-M. Kalhor, A. Dadras, Synthesis, Characterization, and Herbicidal Activities of New 1,3,4-Oxadiazoles, 1,3,4-Thiadiazoles, and 1,2,4Triazoles Derivatives Bearing (R)-5-Chloro-3fluoro-2-phenoxypyridine, J. Heterocycl. Chem., 2013, 50, 220-224.

114-G. X. Sun, M. Y. Yang, Z. H. Sun, H. K. Wu, X. H Liu, Y. Y. Wei, Synthesis and bioactivities of novel 1,3,4-oxadiazole derivatives containing 1,2,3-thiadiazole moiety, Phosphorus. Sulfur. Silicon Relat. Elem., 2014, 189, 1895-1900.

115-K. Dasuri, L. Zhang, J. N. Keller, Oxidative stress, neurodegeneration, and the balance of protein degradation and protein synthesis, Free Radic. Biol. Med., 2013, 62, 170-185.

116-Y. Ünver, H. Gökce, E. Bektaş, F. Çelik, İ. Değirmencioğlu, New bis 1,3,4-oxadiazole derivatives: syntheses, characterizations, computational studies, and antioxidant activities, Can. J. Chem., 2018, 96, 1047-1059.

117-A. C. Sauer, J. G. Leal, S. T. Stefanello, M. T. B. 
Leite, M. B. Souza, F. A. A. Soares, Synthesis and antioxidant properties of organosulfur and organoselenium compounds derived from 5-substituted-1,3,4-oxadiazole/thiadiazole-2-thiols, Tetrahedron Lett., 2017, 58, 87-91.

118-L. Ma, Y. Xiao, C. Li, Z. L. Xie, D. D. Li, Y. T. Wang, Synthesis and antioxidant activity of novel Mannich base of 1,3,4-oxadiazole derivatives possessing 1,4-benzodioxan, Bioorg. Med. Chem., 2013, 21, 6763-6770.

119-Y. Kotaiah, N. Harikrishna, K. Nagaraju, R. C. Venkata, Synthesis and antioxidant activity of 1,3,4-oxadiazole tagged thieno[2,3-d]pyrimidine derivatives, Eur. J. Med. Chem., 2012, 58, 340-345.

120-A. Cavalli, M. L. Bolognesi, Neglected Tropical Diseases: Multi-Target-Directed Ligands in the Search for Novel Lead Candidates against Trypanosoma and Leishmania, J. Med. Chem., 2009, 52, 7339-7359.

121-M. Taha, N. H. Ismail, S. Imran, E. H. Anouar, M. Selvaraj, W. Jamil, Synthesis and molecular modelling studies of phenyl linked oxadiazolephenylhydrazone hybrids as potent antileishmanial agents, Eur. J. Med. Chem., 2017, 126, 1021-1033. 122-M. Taha, N. H. Ismail, M. Ali, U. Rashid,
S. Imran, N. Uddin, Molecular hybridization conceded exceptionally potent quinolinyloxadiazole hybrids through phenyl linked thiosemicarbazide antileishmanial scaffolds: In silico validation and SAR studies, Bioorg. Chem., 2017, 71, 192-200.

123-J. Kaur, M. Soto-Velasquez, Z. Ding, A. Ghanbarpour, M. A. Lill, R. M. van Rijn, Optimization of a 1,3,4-oxadiazole series for inhibition of $\mathrm{Ca} 2+/$ calmodulin-stimulated activity of adenylyl cyclases 1 and 8 for the treatment of chronic pain, Eur. J. Med. Chem., 2019, 162, 568-585.

124-P. N. Tripathi, P. Srivastava, P. Sharma, A. Seth, S. K. Shrivastava, Design and development of novel N-(pyrimidin-2-yl)-1,3,4-oxadiazole hybrids to treat cognitive dysfunctions, Bioorg. Med. Chem., 2019, 27, 1327-1340.

125-S. A. Shahzad, M. Yar, M. Bajda, L. Shahzadi, Z. A. Khan, S. A. R. Naqvi, Synthesis, thymidine phosphorylase inhibition and molecular modeling studies of 1,3,4-oxadiazole-2-thione derivatives, Bioorg. Chem., 2015, 60, 37-41. 